\title{
The fishing and natural mortality of large, piscivorous Bull Trout and Rainbow Trout in Kootenay Lake, British Columbia (2008-2013)
}

\author{
Joseph L Thorley ${ }^{\text {Corresp., }}{ }^{1}$, Greg F Andrusak ${ }^{2}$ \\ 1 Poisson Consulting, Nelson, British Columbia, Canada \\ 2 BC Fish and Wildlife Branch, Ministry of Forests, Lands and Natural Resource Operations, Victoria, British Columbia, Canada \\ Corresponding Author: Joseph L Thorley \\ Email address: joe@poissonconsulting.ca
}

Background. Estimates of fishing and natural mortality are important for understanding, and ultimately managing, commercial and recreational fisheries. High reward tags with fixed station acoustic telemetry provides a promising approach to monitoring mortality rates in large lake recreational fisheries. Kootenay Lake is a large lake which supports an important recreational fishery for large Bull Trout and Rainbow Trout.

Methods. Between 2008 and 2013, 88 large ( $\geq 500 \mathrm{~mm}$ ) Bull Trout and 149 large ( $\geq 500 \mathrm{~mm}$ ) Rainbow Trout were marked with an acoustic transmitter and/or high reward (\$100) anchor tags in Kootenay Lake. The subsequent detections and angler recaptures were analysed using a Bayesian individual state-space Cormack-Jolly-Seber (CJS) survival model with indicator variable selection.

Results. The final CJS survival model estimated that the annual interval probability of being recaptured by an angler was 0.17 (95\% CRI 0.11 - 0.23) for Bull Trout and 0.14 (95\% CRI 0.09 - 0.19) for Rainbow Trout. The annual interval survival probability for Bull Trout was estimated to have declined from 0.91 (95\% CRI 0.76 - 0.97) in 2009 to just 0.46 (95\% CRI $0.24-0.76$ ) in 2013. Rainbow Trout survival was most strongly affected by spawning. The annual interval survival probability was 0.77 (95\% CRI 0.68 0.85) for a non-spawning Rainbow Trout compared to 0.41 (95\% CRI $0.30-0.53$ ) for a spawner. The probability of spawning increased with the fork length for both species and decreased over the course of the study for Rainbow Trout.

Discussion. Fishing mortality was relatively low and constant while natural mortality was relatively high and variable. The results indicate that angler effort is not the primary driver of short-term population fluctations in the Rainbow Trout abundance. Variation in the probability of Rainbow Trout spawning suggests that the spring escapement at the outflow of Trout Lake may be a less reliable index of abundance than previously assumed. Multi-species stock assessment models need to account for the fact that large Bull Trout are more abundant than large Rainbow Trout in Kootenay Lake. 


\title{
The fishing and natural mortality of large, piscivorous Bull Trout and Rainbow Trout in Kootenay Lake, British Columbia (2008-2013)
}

\author{
Joseph L. Thorley ${ }^{1}$ and Greg F. Andrusak ${ }^{2}$ \\ ${ }^{1}$ Poisson Consulting Ltd., Nelson, British Columbia, Canada \\ ${ }^{2}$ BC Fish and Wildlife Branch, Victoria, British Columbia, Canada
}

\& ABSTRACT

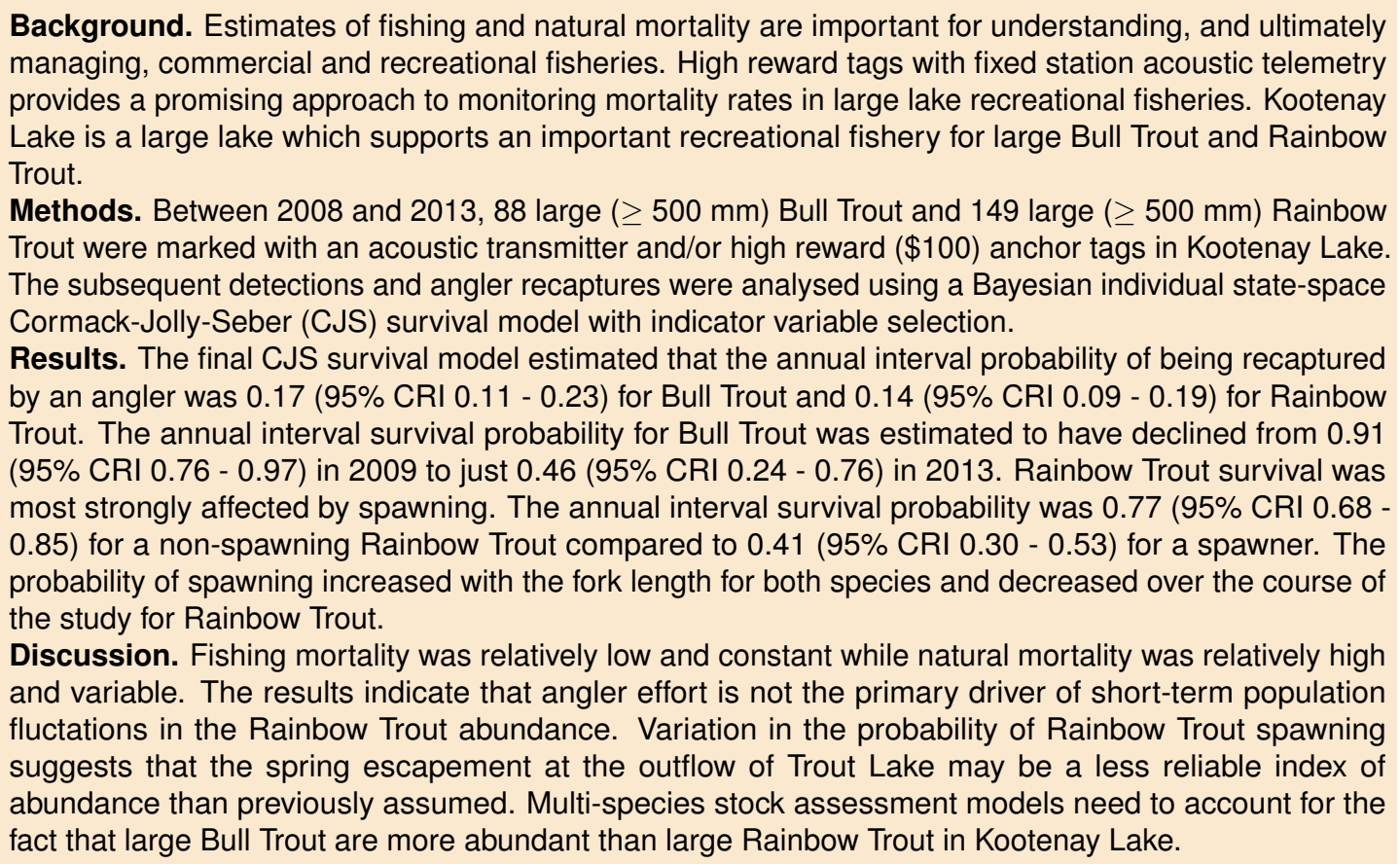
managing, commercial and recreational fisheries. High reward tags with fixed station acoustic telemetry provides a promising approach to monitoring mortality rates in large lake recreational fisheries. Kootenay Lake is a large lake which supports an important recreational fishery for large Bull Trout and Rainbow Trout.

Methods. Between 2008 and 2013, 88 large ( $\geq 500 \mathrm{~mm}$ ) Bull Trout and 149 large ( $\geq 500 \mathrm{~mm}$ ) Rainbow Trout were marked with an acoustic transmitter and/or high reward (\$100) anchor tags in Kootenay Lake. The subsequent detections and angler recaptures were analysed using a Bayesian individual state-space Cormack-Jolly-Seber (CJS) survival model with indicator variable selection.

Results. The final CJS survival model estimated that the annual interval probability of being recaptured by an angler was 0.17 (95\% CRI $0.11-0.23)$ for Bull Trout and 0.14 (95\% CRI $0.09-0.19)$ for Rainbow Trout. The annual interval survival probability for Bull Trout was estimated to have declined from 0.91 (95\% CRI $0.76-0.97)$ in 2009 to just 0.46 (95\% CRI $0.24-0.76)$ in 2013. Rainbow Trout survival was most strongly affected by spawning. The annual interval survival probability was 0.77 (95\% CRI 0.68 $0.85)$ for a non-spawning Rainbow Trout compared to 0.41 (95\% CRI $0.30-0.53)$ for a spawner. The probability of spawning increased with the fork length for both species and decreased over the course of the study for Rainbow Trout.

Discussion. Fishing mortality was relatively low and constant while natural mortality was relatively high and variable. The results indicate that angler effort is not the primary driver of short-term population fluctations in the Rainbow Trout abundance. Variation in the probability of Rainbow Trout spawning suggests that the spring escapement at the outflow of Trout Lake may be a less reliable index of abundance than previously assumed. Multi-species stock assessment models need to account for the fact that large Bull Trout are more abundant than large Rainbow Trout in Kootenay Lake.

\section{INTRODUCTION}

Estimates of fishing $(F)$ and natural mortality $(M)$ are important for understanding, and ultimately managing, commercial and recreational fisheries (Hilborn, 1992; Walters and Martell, 2004). However separating the contributions of $F$ and $M$ to the total mortality $(Z)$ of a fish population is challenging (Quinn and Deriso, 1999). In the case of large lake recreational fisheries, a promising approach (Bacheler et al., 2009) combines a high reward tagging program to provide information on $F$ (Pollock et al., 2001) with an acoustic telemetry study to provide information on $M$ (Pollock et al., 2004).

Kootenay Lake is a large $\left(388 \mathrm{~km}^{2}\right)$ enhanced waterbody in the upper Columbia River drainage that supports a 200,000 rod hour per year recreational fishery (Andrusak and Andrusak, 2012) primarily targetting large ( $\geq 500 \mathrm{~mm}$ ) Bull Trout (Salvelinus confluentus) and Rainbow Trout (Onchorhynchus mykiss). The Bull Trout are an adfluvial population that spawn in the many tributaries of Kootenay Lake (Andrusak and Andrusak, 2014). The large Rainbow Trout, which are often referred to as Gerrard 
Rainbow Trout (Hartman and Galbraith, 1970), represent a genetically distinct (Keeley et al., 2007) piscivorous ecotype (Keeley et al., 2005). Both the Bull Trout and Rainbow Trout can reach trophy size $(\geq 9 \mathrm{~kg})$ in Kootenay Lake.

Kootenay Lake has experienced several anthropogenic shifts in its nutrient loading over the past six decades (Northcote, 1973). In the 1950s and 1960s it was eutrophic due to nutrient pollution. Then in the 1970s pollution reduction and the retention of nutrients in the recently constructed upstream Duncan and Libby reservoirs caused a long-term decline in lake productivity (Daley et al., 1981). As a result Kokanee (Oncorhynchus nerka), which provide the primary food source for the piscivorous trout (Andrusak and Parkinson, 1984), also declined. In response, the North Arm of Kootenay Lake began to be fertilized in 1992 (Schindler et al., 2014). However, between 1997 and 2000 the fertilizer inputs were temporarily experimentally reduced before returning to pre-1997 levels in 2001. Most recently, in 2004, the fertilization program was expanded to also include the South Arm (Schindler et al., 2014).

Since the late 1980s, the large piscivorous Rainbow Trout in Kootenay Lake have exhibited population cycles of approximately seven to eight years in duration (Kurota et al., 2016). Possible explanations for the short-term cycles include angler effort or Kokanee abundance (Kurota et al., 2016). If angling effort is the primary driver then $F$ would be expected to be varying through time. Conversely if Kokanee abundance or another biological factor is responsible then $M$ should be variable. In contrast, relatively little is known about the status of the Bull Trout population; although preliminary analysis of redd counts suggest a decline in Bull Trout spawner abundance from 2009 to 2013 (Andrusak and Andrusak, 2014).

Here we document a combined tag-telemetry study to estimate the natural and fishing mortality of the large $(\geq 500 \mathrm{~mm})$ Bull Trout and Rainbow Trout in Kootenay Lake. A secondary objective was to test whether $F$ and/or $M$ were changing through time. The study commenced in 2008 with a one year pilot program that was followed by three more years (2009-2011) of high reward tagging and acoustic telemetry and then a final two years (2012-2013) of high reward tagging only. The data were analysed using a Bayesian individual state-space formulation (Royle, 2008; Kéry and Schaub, 2011) of the Cormack-Jolly-Seber (CJS) (Cormack, 1964; Jolly, 1965; Seber, 1965) survival model to take into account acoustic detection probabilities, angler recaptures, spawning state and growth. Model selection was achieved by using indicator variable selection (Hooten and Hobbs, 2015). In 2011 a creel survey was conducted on Kootenay Lake (Andrusak and Andrusak, 2012). The recapture rates from the current study are combined with the effort and catch estimates from the creel survey to estimate the catchability and density for both populations.

\section{METHODS}

\section{Study Area}

The main body of Kootenay Lake $\left(116.905^{\circ} \mathrm{E} 49.635^{\circ} \mathrm{S}\right)$ is a large $\left(388 \mathrm{~km}^{2}\right)$, long $(109 \mathrm{~km})$, narrow $(4$ $\mathrm{km}$ ), deep (mean depth c. $100 \mathrm{~m}$ ) volume of water in the upper Columbia River drainage of southeastern British Columbia (Fig. 1). The Duncan-Lardeau River system feeds the North Arm while the Kootenay River feeds the South Arm (Fig. 1). The outlet of the main lake forms the upper end of the shallow West Arm which includes a series of narrow riverine sections. Lake levels and temperatures are influenced by the upstream Duncan and Libby Dams and by the downstream Corra Linn Dam (Hamblin and McAdam, 2003). For more information on Kootenay Lake see Daley et al. (1981), Schindler et al. (2014) and Kurota et al. (2016).

\section{Acoustic Receivers}

The study was made possible by the pre-existence of an acoustic receiver array. The array, which was supplemented so that it included a total of $25 \mathrm{VR} 2(\mathrm{~W}) 81 \mathrm{kHz}$ Vemco® acoustic receivers in Kootenay Lake (Fig. 1), was originally designed to track juvenile White Sturgeon (Acipenser transmontanus) (Neufeld and Rust, 2009). The array has also been used to track fluvial Bull Trout (Paragamian and Walters, 2011) and juvenile Burbot (Lota lota) (Stephenson et al., 2013). An additional three VR2(W) $81 \mathrm{kHz}$ Vemco® acoustic receivers were deployed each year in the Lardeau River at the outflow of Trout Lake (Fig. 1) in April and May to detect spawning Rainbow Trout (Irvine, 1978; Irvine et al., 2013).

The lake receivers were held in position by an anchor and a high pressure trawl float about $30 \mathrm{~m}$ below the surface. The receivers themselves were orientated in a downward direction at a depth of about 45 m. For more information on lake receiver deployment see Neufeld and Rust (2009). At the outflow of 
Trout Lake the three receivers were mounted to bankside submerged structures and orientated across the channel.

\section{Acoustic Transmitters}

Between 2008 and 2011, Bull Trout and Rainbow Trout with a fork length $\geq 500 \mathrm{~mm}$ were tagged with a V13-1L or V13-1LP $81 \mathrm{kHz}$ Vemco® acoustic transmitter. The V13-1L transmitters had a diameter of $13 \mathrm{~mm}$, length of $36 \mathrm{~mm}$ and mass of $11 \mathrm{~g}$ while the V13P-1L transmitters had a diameter of $13 \mathrm{~mm}$, length of $45 \mathrm{~mm}$ and mass of $12 \mathrm{~g}$. In the pilot year (2008) the V13-1L transmitters had a nominal pulse frequency of $60 \mathrm{~s}$ (30-90 s) which resulted in a tag life of 455 days. In all subsquent years the nominal pulse rate was $120 \mathrm{~s}(60-180 \mathrm{~s})$ which resulted in a tag life of 1,239 days for the V13-1L transmitters and 830 days for the V13P-1L transmitters. Recovered transmitters with a remaining tag life of 730 days or more were redeployed in new fish. Approximately six percent of the acoustically tagged fish were tracked using a recovered transmitter.

\section{Reward Tags}

All fish were tagged with an orange $\$ 100$ reward anchor tag (Pollock et al., 2001). Following the pilot year, all but one Bull Trout and two Rainbow Trout were also tagged with a green $\$ 10$ reward anchor tag, a blue standard anchor tag or another $\$ 100$ reward anchor tag to provide information on tag loss (Fabrizio et al., 1999). The anchor tags were Floy® FD-68B T-bar anchor tags with $16 \mathrm{~mm}$ monofilament and 44 $\mathrm{mm}$ tubing. The anchor tags were attached below the dorsal fin on opposite sides using a Floy® Mark III regular pistol grip tagging gun.

To maximize anchor tag reporting (Pollock et al., 2001) the anchor tags displayed a government telephone number. The orange and green reward tags also displayed the text "REWARD \$100" or "REWARD \$10", respectively. The reward tagging program was advertised on posters and in the local media (newspapers, radio and television). Rewards were only paid for returned anchor tags. Anglers were interviewed by phone to determine the date and location of recapture.

\section{Fish Capture and Handling}

Fish were caught by trolling lures with barbless hooks behind a boat. Angled fish were quickly played to the side of the boat, netted, unhooked and placed into a $150 \mathrm{~L}$ cooler of aerated fresh water where they were allowed to recover for approximately 20 minutes. Only individuals with a fork length $\geq 500 \mathrm{~mm}$ that had not suffered hooking damage, were not heavily bleeding and were able to maintain equilibrium were acoustically and/or reward tagged.

Once recovered, angled fish were transferred to a second $150 \mathrm{~L}$ cooler of aerated fresh lake water and clove oil (emulsified in ethanol) at a concentration of $50 \mathrm{mg} / \mathrm{L}$ (Anderson et al., 1997; Prince and Powell, 2000). Fish were then held in the second cooler for approximately 150 seconds until they exhibited total loss of equilibrium and no longer responded to squeezing the caudal peduncle (Gutowsky et al., 2013, 2016).

The anaesthetised fish was then immediately placed upside down on a V-board where its gills were gently irrigated using a wash bottle filled with water from the second cooler. The acoustic tag and surgical equipment had been sterilised previously by soaking for approximately 20 minutes in $70 \%$ ethanol while the fish was recovering from capture. The acoustic tag and surgical equipment were rinsed with sterile saline solution prior to surgery to remove the ethanol. A scapel blade (number 11) was used to make an incision of approximately $50 \mathrm{~mm}$ in length midway between the pelvic and pectoral fish, close to and parallel to the mid-ventral line. After insertion of the acoustic tag, an Ethicon ${ }^{\circledR}$ suture with $700 \mathrm{~mm}$ of 1.5 metric polydioxanone monofilament and a $19 \mathrm{~mm} 3 / 8$ circle reverse cutting needle was used to close the incision with two or three interrupted stitches. Midway through stitching the irrigation wash bottle was replaced with one filled with fresh lake water.

Following surgical implantation of an acoustic transmitter, each fish was measured $( \pm 1 \mathrm{~mm})$ and returned to the recovery cooler. While the fish was recovering it was anchor tagged and adipose clipped. All tagged fish were allowed to recover from surgery for approximately 20 minutes before being released within $500 \mathrm{~m}$ of the point of capture. In 2012 and 2013, fish were anchor tagged only and so were not anesthetised or adipose clipped. Fish were obtained under scientific collection permits (CB08-43988, CB09-53420, CB10-61021, CB11-69505, CB12-76723) issued by the British Columbia Ministry of Forests Lands and Natural Resource Operations (MFLNRO). 


\section{Data Manipulation Raw Data}

The acoustic receiver VRL download files were processed using Vemco® VUE software to calculate the number of hourly detections of each transmitter by each acoustic receiver. The reported recaptures were recorded by MFLNRO staff and the rewards administered by the Freshwater Fish Society of British Columbia (FFSBC). Based on lake geomorphology and the locations of the receivers (Fig. 1) the study area was divided into 30 sections (Fig. 2).

\section{Hourly Receiver Data}

The hourly detection, receiver deployment, fish capture and recapture data sets and sectional shapefiles were manipulated using R version 3.3.2 (R Core Team, 2015). During data manipulation, two or less detections of a fish at a receiver in an hour or any detections after the expected tag life were discarded. The resultant clean and tidy (Wickham, 2014) data sets were bundled together in an R data package called klexdatr (Article S1).

\section{Daily Sectional Data}

The hourly receiver detection data were then aggregated into daily sectional detection data using the lexr $\mathrm{R}$ package (Article S1). During the aggregation process, acoustically tagged individuals that 30 days after release were no longer detected or were only detected at a single section were classified as post-release mortalities and were excluded (Hightower et al., 2001). Detections of the same fish in more than one section (7\% of the total), were resolved in favour of the section with the most detections. Ties were broken by choosing the section with the least receivers and if still tied the smaller section (sectional areas were unique). The total percent receiver coverage of each section in each interval was calculated (Fig. 3) assuming a detectional radius of $500 \mathrm{~m}$ (Gutowsky et al., 2013, 2016; Huveneers et al., 2015).

\section{Seasonal Sectional Data}

The lexr package was then used to group the daily data into seasonal periods for analysis. Following Gutowsky et al. (2013), the seasons were winter (January-March), spring (April-June), summer (July-September) and autumn (October-December). The final data included logical matrices indicating for each fish in each seasonal period whether it was monitored (active acoustic transmitter) and/or reported (recaptured) and whether it moved (detected in two or more sections) and/or spawned.

Spawning in Bull Trout was identified by a hiatus in detections for at least four weeks during August and September when the fish was deemed to have moved out of the main lake (O'Brien, 2001; Andrusak and Andrusak, 2014). For Rainbow Trout spawning was identified by either a detection in April or May at the outflow of Trout Lake (section S02) or a hiatus in detections for three or more weeks during April and May (Irvine, 1978; Irvine et al., 2013) with the bracketing detections occuring in the top 9\% of Kootenay Lake (sections S07-S09).

\section{Statistical Analysis CJS Model}

The probabilities of being recaught (and reported) by an angler versus dying of other causes were estimated from the seasonal data using an individual state-space (Royle, 2008; Kéry and Schaub, 2011) Cormack-Jolly-Seber (CJS) (Cormack, 1964; Jolly, 1965; Seber, 1965) survival model. In the individual state-space formulation of the CJS model, the $i$ th individual is alive when it is initially tagged at time period $f_{i}$, e.g.

$$
z_{i, f_{i}}=1 .
$$

Its latent state (alive versus dead) at subsequent periods is modelled as the outcome of a series of Bernoulli trials

$$
z_{i, t+1} \sim \operatorname{Bernoulli}\left(z_{i, t} \cdot \phi_{i, t}\right)
$$

where $\phi_{i, t}$ is the predicted survival for the $i$ th fish in the $t$ th time period. An individual that is alive at period $t$ also has a probability $\rho_{i, t}$ of being recaptured, i.e.,

$$
y_{i, t} \sim \operatorname{Bernoulli}\left(z_{i, t} \cdot \rho_{i, t}\right) .
$$




\section{Base Model}

In the base model of the current study, $\rho_{i, t}$ is the probability of being recaptured (and reported) by an angler. To reduce the number of necessary assumptions, reported recaptures are excluded from the analysis for all subsequent time periods, i.e., subsequent detections or recaptures of any released individuals were ignored. In addition, a living individual with an active transmitter $\left(T_{i, t}=1\right)$ also has a probability $\left(\delta_{i, t}\right)$ of being detected moving $\left(m_{i, t}\right)$ between sections by the receiver array

$$
m_{i, t} \sim \operatorname{Bernoulli}\left(z_{i, t} \cdot T_{i, t} \cdot \delta_{i, t}\right) .
$$

Finally, in the spawning season $\left(S_{i, t}=1\right)$ a fish has a probability $\kappa_{i, t}$ of entering the state of spawning $\left(x_{i, t}=1\right)$ for the period

$$
x_{i, t} \sim \operatorname{Bernoulli}\left(z_{i, t} \cdot S_{i, t} \cdot \kappa_{i, t}\right) .
$$

In the base model, the terms $\phi_{i, t}, \rho_{i, t}, \delta_{i, t}$ and $\kappa_{i, t}$, which represent probabilities, are specified by four parameters, i.e.,

$$
\begin{aligned}
& \operatorname{logit}\left(\phi_{i, t}\right)=\beta_{\phi 0}, \\
& \operatorname{logit}\left(\rho_{i, t}\right)=\beta_{\rho 0}, \\
& \operatorname{logit}\left(\delta_{i, t}\right)=\beta_{\delta 0}
\end{aligned}
$$

and

$$
\operatorname{logit}\left(\kappa_{i, t}\right)=\beta_{\kappa 0}
$$

where

$$
\operatorname{logit}(p)=\log \left(\frac{p}{1-p}\right) .
$$

\section{Full Model}

The full model extends the base model through the inclusion of seven additional parameters $\left(\beta_{\kappa L}, \beta_{\phi x}\right.$, $\beta_{\delta S}, \beta_{\kappa Y}, \beta_{\rho Y}, \beta_{\phi Y}$ and $\left.\beta_{\delta Y}\right)$. The first parameter $\left(\beta_{\kappa L}\right)$ allows the log odds probability of spawning to vary with the calculated fork length $\left(L_{i, t}\right)$

$$
\operatorname{logit}\left(\kappa_{i, t}\right)=\beta_{\kappa 0}+\beta_{\kappa L} \cdot L_{i, t}
$$

while the second $\left(\beta_{\phi x}\right)$ allows the log odds survival to vary with spawning

$$
\operatorname{logit}\left(\phi_{i, t}\right)=\beta_{\phi 0}+\beta_{\phi x} \cdot x_{i, t} .
$$

The fork lengths were calculated based on the measured length at capture $L_{i, f_{i}}$ plus the length increment expected under a Von Bertalanffy Growth Curve (Walters and Martell, 2004)

$$
L_{i, t}=L_{i, f_{i}}+\left(L_{\infty}-L_{i, f_{i}}\right)\left(1-e^{-0.25 \cdot k\left(t-f_{i}\right)}\right)
$$

where the 0.25 in the exponent adjusts for the fact that there are four time periods (seasons) per year. The calculation assumes a $L_{\infty}$ of $1,000 \mathrm{~mm}$ with a $k$ of 0.13 for Bull Trout and a $k$ of 0.19 (Andrusak and Thorley, 2014) for Rainbow Trout.

The third additional parameter $\left(\beta_{\delta S}\right)$ allows the log odds probability of being detected moving to vary with the spawning season

$$
\operatorname{logit}\left(\delta_{i, t}\right)=\beta_{\delta 0}+\beta_{\delta S} \cdot S_{i, t}
$$

while the last four parameters $\left(\beta_{K Y}, \beta_{\rho Y}, \beta_{\phi Y}\right.$ and $\beta_{\delta Y}$ ) allow the probability of spawning, recapture, survival, and detection moving between sections to vary with the standardised year $\left(Y_{i, t}\right)$, i.e,

$$
\operatorname{logit}\left(\kappa_{i, t}\right)=\beta_{\kappa 0}+\beta_{\kappa Y} \cdot Y_{i, t} .
$$

The parameters in the full model are defined in Table 1. 
Parameter Estimation. The parameters were estimated using Bayesian methods (Ntzoufras, 2009; Kéry, 2010; Kéry and Schaub, 2011). The prior distribution for each parameter was a normal distribution with a mean of 0 and a standard deviation of 3 , i.e.,

$$
\beta_{\kappa 0} \sim \operatorname{Normal}(0,3)
$$

The posterior distributions of the parameters were estimated using a Monte Carlo Markov Chain (MCMC) algorithm. To avoid non-convergence of the MCMC process, five chains were run, starting at randomly selected initial values. Each chain was run for at least $10^{5}$ iterations with the first half of the chain discarded for burn-in followed by further thinning to leave a grand total of 10,000 samples. Convergence was confirmed by ensuring that $\hat{R} \leq 1.05$ for each of the parameters in the model (Brooks and Gelman, 1998; Kéry and Schaub, 2011).

The vagueness of the priors was assessed by a sensitivity analysis (Kéry and Schaub, 2011). More specifically, the model was refitted with the prior distribution for each parameter a normal distribution with a mean of 0 and a standard deviation of 6 . The sensitivity of the posteriors to the change in priors was assessed using $\hat{R}$. Although developed to quantify the convergence between chains, $\hat{R}$ can also be used as a metric of the convergence between models by combining all the samples for each model. The vagueness of the priors was confirmed by ensuring that the between model $\hat{R}$ values were all $\leq 1.2$. A higher minimum $\hat{R}$ value was accepted for the between model (than the within model convergence) because the purpose of the test was to confirm that the posteriors were not unduly altered by the change in the priors, i.e., except in the case of simple models with lots of data it is not realistic to expect that a substantial change in the priors will have no effect at all on any of the posteriors. The chosen $\hat{R}$ value of 1.2 is within the accepted range of values used to confirm the convergence of chains within a single model (Kéry and Schaub, 2011).

The reported point estimates are the mean and the $95 \%$ credible intervals (CRIs) are the 2.5 and 97.5\% quantiles (Gelman, 2014). Unless stated otherwise all presented and plotted estimates are for a representative individual which in the current study was judged to be a $650 \mathrm{~mm}$ non-spawner in the autumn of 2011 .

\section{Model Selection}

Model selection was achieved by using indicator variable selection (Hooten and Hobbs, 2015) to estimate probabilities for the inclusion of the seven additional parameters from the full model in a final model. More specifically, "stochastic search variable selection" (George and McCulloch, 1993; Hooten and Hobbs, 2015) was used to assign an indicator variable to each parameter such that

$$
\begin{aligned}
& \gamma_{\kappa L} \sim \operatorname{Bernoulli}(1 / 2) \\
& \beta_{\kappa L} \sim \gamma_{\kappa L} \cdot \operatorname{Normal}(0,3)+\left(1-\gamma_{\kappa L}\right) \operatorname{Normal}(0,0.03)
\end{aligned}
$$

In other words if the indicator is 1 then the parameter is drawn from the standard vague prior, otherwise the parameter is drawn from a prior that is so constrained that its value is effectively zero. The values of $\gamma_{\rho Y}$ and $\gamma_{\phi Y}$ indicate the support for a change in $F$ and $M$, respectively, over the course of the study.

Software. The analyses were performed using R version 3.3.2 (R Core Team, 2015), JAGS 4.2.0 (Plummer, 2015) and the klexr R package (Article S1), which was developed specifically for this paper .

\section{Model Assumptions}

The validity of a statistical model's estimates depends on the extent to which its assumptions are violated (Kéry and Schaub, 2011). Like the standard CJS model, the modified form used in the current analysis assumes that

1. The tagged individuals are a random sample from the population.

2. There are no effects of tagging.

3. There is no loss of anchor or acoustic tags.

4. All individuals are correctly identified.

5. There is no emigration out of the main lake. 
6. There are no unmodelled individual differences in the probability of recapture in each time interval.

7. There are no unmodelled individual differences in the probability of survival in each time interval.

8. The fate of each individual is independent of the fate of any other individual.

9. The sampling periods are instantaneous and all individuals are immediately released.

In addition, the modified form used in the current study also assumes that

10. There are no unmodelled individual differences in the probability of a living individual with an active acoustic transmitter being detected moving among sections in each time period.

11. Anglers report all anchor tags.

12. Spawning events are correctly identified.

13. Growth increments are correctly calculated.

The extent to which each assumption may have been violated was assessed based on the literature and, when available, auxilary data. In particular, the random nature of the population sample was assessed by plotting the spatial distribution of captures, daily detections and recaptures. The extent of any outmigration was evaluated from the proportion of acoustically tagged individuals last detected at the top of the North Arm (S07), bottom of the South Arm (S32) and at the upper end of the West Arm (S20). Only individuals that were last detected at least 120 days before the end of their transmitter life and were not subsequently recaptured were considered to be possible outmigrants. Finally, anchor tag loss was estimated from the proportion of double-tagged individuals that had lost a anchor tag at recapture using a simple Bayesian zero-truncated binomial tag-loss model (Fabrizio et al., 1999).

\section{RESULTS}

\section{Fish Captures and Recaptures Captures}

Between 2008 and 2013, 88 large ( $\geq 500 \mathrm{~mm}$ ) Bull Trout and 149 large ( $\geq 500 \mathrm{~mm}$ ) Rainbow Trout were marked with at least one $\$ 100$ reward anchor tag (Tables 2-3). A total of 69 of the Bull Trout and 114 of the Rainbow Trout were also acoustically tagged. Most Bull Trout were caught in the central portion of the main lake or the top of the North Arm (Fig. S1) while most Rainbow Trout were caught in the central portion of the main lake (Fig. S2).

\section{Post-release Mortalities}

Of the acoustically tagged individuals five (7\%) of the Bull Trout and 28 (25\%) of the Rainbow Trout were no longer detected moving between sections 30 days after release. They were deemed to be post-release mortalities and were excluded from the data. The daily detections are plotted by section and date in Figure 4 for the remaining 83 Bull Trout and 121 Rainbow Trout.

\section{Detections}

The spatial distribution of the daily detections indicates that fish use of the main lake was relatively evenly distributed for both Bull Trout (Fig. S3) and Rainbow Trout (Fig. S4). A grand total of 27 acoustically tagged Bull Trout, which were not subsequently recaught, were last detected moving in the main lake 120 days before the end of their transmitter life (Table 4). Of the 27 Bull Trout, seven (26\%) were last detected moving at section S07, one (4\%) at S20 and zero (0\%) at S32. For Rainbow Trout, the grand total was 48 individuals (Table 5), of which seven (15\%) were last detected at section S07, four (8\%) at S20 and three (6\%) at S32.

\section{Recaptures}

A total of 26 of the 83 Bull Trout and 24 of the 121 Rainbow Trout were reported to have been recaught by an angler (Fig. 4). In the main lake, most of the Bull Trout were recaught in the central portion or the top of the North Arm (Fig. S5). In contrast the Rainbow Trout recaptures were relatively evenly distributed throughout the main lake with the exception of the most northerly sections of the North Arm and the most southerly sections of the South Arm (Fig. S6). 
Of the 25 Bull Trout recaptures that had been initially tagged with a $\$ 100$ and a $\$ 10$ tag, 18 had both anchor tags, three had just the $\$ 100$ tag and four had just the $\$ 10$ tag. For the 22 equivalent Rainbow Trout recaptures, 20 had both anchor tags, zero had just the $\$ 100$ tag and two had just the $\$ 10$ tag. Analysis of the number of individuals with one versus two anchor tags using the simple Bayesian tag-loss model estimates the probability of a single-tagged individual losing its anchor tag between release and recapture to be 0.18 (95\% CRI 0.08 - 0.32) for Bull Trout and 0.07 (95\% CRI $0.01-0.17$ ) for Rainbow Trout. The corresponding probability of a double-tagged individual losing both its anchor tags (assuming the fates of both tags are independent) is 0.04 (95\% CRI 0.01 - 0.10) and 0.006 (95\% CRI 0.000 - 0.027), for Bull Trout and Rainbow Trout, respectively.

\section{Parameter Estimates and Model Selection Parameter Estimation}

Model convergence was confirmed by an $\hat{R} \leq 1.02$ for Bull Trout and $\leq 1.02$ for Rainbow Trout. The vagueness of the priors was confirmed by a between model $\hat{R} \leq 1.05$ for Bull Trout and $\leq 1.12$ for Rainbow Trout.

\section{Recapture}

The final CJS survival model estimated that the annual probability of being recaptured (and reported) by an angler $(\rho)$ was 0.17 (95\% CRI 0.11 - 0.23) for Bull Trout (Table 6) and 0.14 (95\% CRI 0.09 - 0.19) for Rainbow Trout (Table 7). The indicator variable probabilities for $\gamma_{\rho Y}$ were 0.09 and 0.09 for each species, respectively, revealing little to no support for a change in the probability of recapture with year.

\section{Survival}

The survival probability for Bull Trout was largely unaffected by spawning $\left(\gamma_{\phi \kappa}=0.29\right)$ but changed over the course of the study $\left(\gamma_{\phi Y}=0.95\right)$. More specifically, the annual Bull Trout survival probability was estimated to have declined from 0.91 (95\% CRI 0.76 - 0.97) in 2009 to just 0.46 (95\% CRI 0.24 - 0.76) in 2013 (Figure 5).

In contrast, Rainbow trout survival was strongly affected by spawning $\left(\gamma_{\phi \kappa}=1.00\right)$ and may have changed over the course of the study $\left(\gamma_{\phi Y}=0.76\right)$. If present, the change in survival over time was a decline (Figure 5). The CJS model estimated that spawning reduced the annual Rainbow Trout survival probability from 0.77 (95\% CRI 0.68 - 0.85) to 0.41 (95\% CRI 0.30 - 0.53) (Figure 6).

\section{Spawning}

For both species, the probability of spawning was clearly dependent on the fork length as $\gamma_{\kappa L}=0.97$ for Bull Trout and 1.00 for Rainbow Trout. Figure 7 indicates that the probability of spawning increases from $0.40(95 \%$ CRI $0.16-0.75)$ for a $500 \mathrm{~mm}$ Bull Trout to 0.94 (95\% CRI 0.78 - 0.99) for a $800 \mathrm{~mm}$ Bull Trout. The equivalent values for Rainbow Trout are 0.00 (95\% CRI 0.00 - 0.00) and 0.90 (95\% CRI 0.76 0.98), respectively.

There was little support $\left(\gamma_{\kappa Y}=0.23\right)$ for a change in the probability of spawning for Bull Trout from 2009 to 2013. However, in contrast, there was strong support $\left(\gamma_{K Y}=1.00\right)$ for a decline in the probability of spawning for Rainbow Trout over the course of the study (Fig. 8).

\section{Movement}

The last key parameter in the CJS model - the probability of being detected moving among sections while alive with an active transmitter - varied by spawning season for Bull Trout $\left(\gamma_{\delta S}=1.00\right)$ but not Rainbow Trout $\left(\gamma_{\delta S}=0.20\right)$. In the case of Bull Trout, the probability was $0.49(95 \%$ CRI $0.40-0.58)$ for being detected moving during the summer spawning season compared to 0.91 (95\% CRI 0.88 - 0.94) during the other seasons. The probability of being detected moving was 0.95 (95\% CRI $0.93-0.97$ ) for Rainbow Trout. Over the course of the study, the probability of being detected moving among sections may have $\left(\gamma_{\delta Y}=0.64\right)$ declined $\left(\beta_{\delta Y}=-0.37\right)$ for Bull Trout but not Rainbow Trout $\left(\gamma_{\delta Y}=0.10\right)$.

\section{Fishing and Natural Mortality}

If all recaptures are harvested then $F=-\log (1-\rho)$ and the estimated annual instantaneous fishing mortality $(F)$ is 0.18 (95\% CRI 0.12 - 0.26) for Bull Trout and 0.15 (95\% CRI 0.10 - 0.22) for Rainbow Trout. Similarly, as $M=-\log (\phi)$ the estimated annual instantaneous natural mortality $(M)$ for a Bull Trout was 0.09 (95\% CRI $0.27-0.03$ ) in 2009 and 0.78 (95\% CRI $1.44-0.27)$ in 2013. For Rainbow Trout $M$ was 0.88 (95\% CRI 1.20 - 0.64) for a spawner and 0.27 (95\% CRI 0.39 - 0.17) for a non-spawner. The natural mortality is plotted by fork length in Figure 9. 


\section{Catchability}

The creel survey estimated that in 2011, a grand total of 189,457 angler hours (and 201,434 rod hours) were expended fishing Kootenay Lake (Andrusak and Andrusak, 2012), which corresponds to an angler effort (E) of 4.88 angler-hr.ha ${ }^{-1} \cdot \mathrm{yr}^{-1}$. If the catchability coefficient $(q)$ is defined to be the probability of (re)capture $(\rho)$ per unit of effort (Ward et al., 2013), i.e.,

$$
q=\frac{\rho}{E}
$$

then, in Kootenay Lake in 2011, $q=0.034\left(95 \%\right.$ CRI 0.023 - 0.047) angler- $\mathrm{hr}^{-1} \cdot \mathrm{ha}^{-1} \cdot \mathrm{yr}^{-1}$ for Bull Trout and 0.028 (95\% CRI 0.019 - 0.040) angler-hr ${ }^{-1} \cdot \mathrm{ha}^{-1} \cdot \mathrm{yr}^{-1}$ for Rainbow Trout.

\section{Density}

The creel survey estimated that 4,845 large $(\geq 500 \mathrm{~mm}$ ) Bull Trout and 3,320 large Rainbow Trout were caught by anglers (Andrusak and Andrusak, 2012). Given the estimated recapture rates, the catches suggest that the density of large Bull Trout in Kootenay Lake in 2011 was 0.75 fish.ha $^{-1}$ and the density of large Rainbow Trout was 0.63 fish.ha ${ }^{-1}$.

\section{DISCUSSION}

\section{Model Reliablity}

The reliability of any model's estimates depends on the extent to which its assumptions are met. If none of the CJS model's assumptions are violated then, the results indicate that the potential fishing mortality, if anglers harvest all fish, was $F=0.18$ for Bull Trout and $F=0.15$ for Rainbow Trout; that the natural mortality increased from $M=0.09$ to $M=0.78$ over the course of the study for Bull Trout; and that for Rainbow Trout, spawning increased $M$ from 0.27 to 0.88 . The following paragraphs discuss each of the assumptions of the CJS model together with the implications of any violations for the mortality estimates.

Sample The model assumes that the tagged individuals are a random sample from the population. The distribution of captures shows that fish were not sampled from all areas equally (Figs. S1-S2). However, the detections of acoustically tagged fish (Figs S3-S4) indicated a high degree of mixing between areas. The possibility that fish may have differed in their susceptibility to (re)capture by angling is discussed below.

Tagging The second assumption is that there are no effects of tagging. To reduce the chances of post-release mortality inflating $M$, fish that were no longer detected moving between sections 30 days after release were excluded from the analysis (Hightower et al., 2001). The fact that $7 \%$ of the Bull Trout versus $25 \%$ of Rainbow were judged to be post-release mortalities suggests that in the short-term at least Bull Trout are less affected by capture, handling and surgery. To ensure any longer-term effects of tagging were minimal, the transmitter to body weight ratio was $\leq 0.9 \%$ (Brown et al., 1999). Nonetheless, it is possible that tagging could have increased natural or fishing mortality or reduced the probability of spawning due to infection or increased energetic expenditures.

Anchor Tag and Transmitter Loss The CJS model assumed that there was no anchor tag or transmitter loss (Brenden et al., 2010). To minimize anchor tag loss, all fish were double-tagged. Analysis of double versus single-tagged recaptures indicates that the probability of losing both anchor tags was $4 \%$ for Bull Trout and $0.6 \%$ for Rainbow Trout. The higher loss rate for Bull Trout may be due to the spawning migration they undertake up steep turbulent tributaries (Andrusak and Andrusak, 2014). The exclusion of fish that had ceased moving within 30 days of initial capture reduced the chances that transmitter loss would affect the mortality estimates (Hightower et al., 2001).

Identification Anglers were required to return all tags. Consequently it is unlikely that fish were misidentified.

Emigration The model assumed that there was no movement outside of the main lake other than temporary seasonal spawning migrations by Bull Trout in the summer and Rainbow Trout in the spring. Bull Trout spawn in tributaries to Kootenay Lake (Andrusak and Andrusak, 2014) as well as tributaries to Trout Lake and Duncan Reservoir (O'Brien, 2001). The seven Bull Trout that were last detected at the top of the North Arm (sections S07 and S09) in the spring (Table 4) may have been early-leaving spawners 
headed to Trout Lake or Duncan Reservoir (O'Brien, 2001) that failed to return. The implications of the misidentification of spawning events is discussed below. The 18 Rainbow Trout that were last detected in the spring at the top of the North Arm or at section S02 at the outflow of Trout Lake (Table 5) are accounted for as spawning mortalities by the model. With the exception of the seven spring Bull Trout migrants at the top of the North Arm there is no indication of any significant movement outside the main lake other than temporary seasonal spawning migrations that are accounted for by the model.

Recapture A key assumption of all mark-recapture studies is that there are no unmodelled individual differences in the probability of (re)capture in each time interval (Biro, 2013). As is often the case, the reliance on a single capture method means it is not possible to test this assumption (Biro, 2013). Depending on whether any individual differences were fixed or learned the estimated potential fishing mortality would be an over or under-estimate, respectively (Askey et al., 2006; Biro, 2013).

Survival The full model allowed survival to vary with spawning status and year. Simulations by Matechou et al. (2013) indicate that the survival estimates are likely to be robust to any remaining time-dependent variation.

Independence Individuals exhibited no obvious shoaling or coordination of movements other than spawning migrations. Consequently the fate of each individual was likely independent of the fate of any other individual.

Instantaneous While individuals were almost immediately released, the sampling periods for captures, recaptures and detections were effectively continuous. However, because the seasonal survival was high ( $\geq 82 \%$ for Bull Trout and $\geq 80 \%$ for Rainbow Trout) and because the purpose was to estimate overall annual survival across four seasonal time periods, substantial biases are not expected (Barbour et al., 2013).

Movement The CJS model assumes that mortalities exhibit no movement. Consequently if the model was to overestimate the probability of a living individual with an active transmitter being detected moving between sections then $M$ would also be overestimated. However, this is unlikely for three reasons. Firstly, the model allowed the probability of movement to vary with spawning season and year. Secondly, the seasonal probability of detecting an individual moving between sections was relatively high $(91 \%$ for Bull Trout and 95\% for Rainbow Trout). Finally, the state-space component of the model means that a temporarily inactive individual or one that is subsequently recaptured will not be misidentified as a natural mortality. Consequently any bias in $M$ is expected to be small.

Reporting To maximize the tag reporting rate, which was assumed to be $100 \%$, at least one of the tags was worth $\$ 100$ tag (Bacheler et al., 2009). Previous studies on Common Snook (Centropomus undecimalis) in Florida in the late 1990s (Taylor et al., 2006) and multiple freshwater fish species in Idaho from 2006 to 2009 (Meyer et al., 2012) suggest that $\$ 100$ is sufficient to achieve reporting rates of approximately $99 \%$.

Spawning The model assumed that spawning events are correctly identified. Large Rainbow Trout from Kootenay Lake almost exclusively spawn at the head of the Lardeau River (Irvine, 1978; Irvine et al., 2013). As this spawning area was acoustically monitored duing the spring it is likely that most of the Rainbow Trout spawning events were correctly identified.

For Bull Trout the situation is more complicated. Large Bull Trout from Kootenay Lake spawn in multiple tributaries of Kootenay Lake, Trout Lake and Duncan Reservoir (O'Brien, 2001; Andrusak and Andrusak, 2014). Consequently it was not possible to monitor spawning locations and spawning was inferred by a hiatus in detections for four or more weeks during August and September. As a result only fish which successfully returned to Kootenay Lake in the fall post-spawning were identified as spawners. Bull Trout that succumbed to spawning-related injuries, stress or predation prior to returning to Kootenay Lake were identified as inlake natural mortalities As a result $M$ is likely biased high for non-spawning Bull Trout and biased low for spawners. This bias may explain why an effect of spawning on mortality was not detected for Bull Trout.

Growth The model assumed that growth was described by a seasonal Von Bertalanffy Growth Curve with a $L_{\infty}$ of $1,000 \mathrm{~mm}$ and a $k$ of 0.13 for Bull Trout and a $k$ of 0.19 for Rainbow Trout. The curve for Bull Trout was partly based on large Bull Trout in Adams Lake, British Columbia (Bison et al., 2003). 
The growth curve for Rainbow Trout was based on lake specific data (Andrusak and Thorley, 2014) and is likely a good approximation.

\section{Mortality Estimates}

The implications of any violations of the assumptions are negligible for the mortality estimates with two exceptions. The reliance on a single capture method means that $F$ could be an over or under-estimate for either or both species. Similarly, the difficulty identifying Bull Trout spawners means that spawning Bull Trout may experience a higher $M$ than non-spawners.

\section{Fishing Mortality}

The actual fishing mortalities are dependent on the release and handling mortality rates. Taken at face value the estimates from the CJS model indicate that if anglers were to harvest all fish, then the annual instantaneous fishing mortality would be approximately $F=0.18$ for Bull Trout and $F=0.15$ for Rainbow Trout. The corresponding annual interval fishing mortalities are $17 \%$ and $14 \%$, respectively. The creel survey calculated that in 2011 anglers released $40 \%$ of the Bull Trout and $62 \%$ of the Rainbow Trout they captured (Andrusak and Andrusak, 2012). Consequently, if large fish are released at the same rate as small fish and there are no post-release mortalities, then the effective annual interval fishing mortalities would be approximately $10 \%$ for Bull Trout and 5\% for Rainbow Trout.

\section{Post-Release Mortality}

The current study indicates that the large Bull Trout in Kootenay Lake are relatively robust to angling and surgical implantation of an acoustic transmitter with a 30 day post-release mortality of $7 \%$. For comparison, Post et al. (2003) in their age-structured model of an adfluvial bull trout population presumed post-release mortality was $10 \%$ but considered values of $2 \%$ and $25 \%$. The current study estimated that large Rainbow Trout experience a post-release mortality of $25 \%$. For comparison, meta-analyses indicate that the mean post-release mortality in salmonid recreational fisheries is $16-18 \%$ although the distribution is positively skewed with most estimates $\leq 11 \%$ (Bartholomew and Bohnsack, 2005; Huhn, Daniel and Arlinghaus, Robert, 2011). It is worth noting that the current estimates include surgical implantation of a acoustic transmitter and may therefore be inflated relative to the post-release mortality of fish caught-and-released by recreational anglers. It is however also possible that the care taken playing, landing and recovering the fish resulted in a comparable or even lower post-release mortality rate than in the recreational fishery.

\section{Catchability}

Remarkably few estimates of catchability have been published for large piscivorous trout. A notable exception is Post et al. (2003) who based on creel data from Lower Kananaskis Lake and experimental fishery data from Marie Lake and Quirk Creek considered a $q$ of 0.07 fish caught.vulnerable fish ${ }^{-1}$.angler$\mathrm{hr}^{-1} \cdot \mathrm{ha}^{-1} \cdot \mathrm{yr}^{-1}$ to be representative for Bull Trout. They assumed fish were invulnerable to capture at $\leq$ $200 \mathrm{~mm}$ and completely vulnerable by $400 \mathrm{~mm}$. Their nominal value of 0.07 is more than double the current Bull Trout estimate of 0.034 angler- $\mathrm{hr}^{-1} \cdot \mathrm{ha}^{-1} \cdot \mathrm{yr}^{-1}$. However, Post et al. (2003) did consider the possibility that $q$ ranged between 0.035 and 0.14 . The reasons for the relatively low catchability of Bull Trout in Kootenay Lake are unknown but could include less efficient angling methods (anglers primarily target Rainbow Trout) or more uniform fish distributions.

Catchability is typically strongly negatively related to the population density - a phenomenon known as hyperstability (Ward et al., 2013). Based on a meta-analysis of Lake Trout (Salvelinus namaycush) in 12 lakes in Ontario, Canada, Shuter et al. (1998) modelled the relationship between catchability and density $(D)$ using a modified form of the equation

$$
q=\exp \left(-\frac{0.14 \cdot E}{1+0.35 \cdot D}\right) \cdot E^{-1}
$$

In Kootenay Lake in 2011, Bull Trout occured at a density of 0.75 fish.ha ${ }^{-1}$ and experienced an effort of 4.88 angler-hr.ha ${ }^{-1} \cdot \mathrm{yr}^{-1}$. If large Bull Trout have the same catchability as Lake Trout, Equation 20 predicts a catchability of 0.12 angler-hr ${ }^{-1} \cdot \mathrm{ha}^{-1} \cdot \mathrm{yr}^{-1}$. Although less then the upper range of 0.14 considered by Post et al. (2003), 0.12 is still much higher than the estimated value of 0.034 angler-hr ${ }^{-1} \cdot \mathrm{ha}^{-1} \cdot \mathrm{yr}^{-1}$.

Ward et al. (2013) concluded that hyperstability for stocked Rainbow Trout in 18 British Columbian lake was caused by differences in angler skill with less experienced anglers tending to target lakes with 
higher fish densities. The lakes were all small waterbodies $(<45 \mathrm{ha})$ with high fish densities $(>15$ fish.ha ${ }^{-1}$ ) and no natural recruitment. As the predictions were for small insectivorous trout at high densities they could not be reliably extrapolated to large piscivorous Rainbow Trout. Nonetheless, Ward et al.'s (2013) findings suggest that Catch-Per-Unit-Effort may need to be scaled by angler effort when attempting to model Bull Trout and Rainbow Trout abundance in Kootenay Lake.

\section{Inter-annual Variability}

There was little to no support for a change in the fishing mortality for either Bull Trout or Rainbow Trout over the course of the study. This finding is important because, as discussed below, it suggests that angler effort is not the primary driver of any short-term fluctuations.

\section{Natural Mortality}

Post et al. (2003) assumed a constant annual instantaneous natural mortality of 0.20 for their Bull Trout population model. The estimate was based on the observed mortality of mature Bull Trout in Lower Kananaskis Lake and Shuter et al.'s (1998) estimates for Lake Trout. Shuter et al. (1998) tabulated estimates of $M$ from 12 lakes. The largest value was 0.4 while the remaining 11 were between 0.12 and 0.25 . For comparison, the CJS model estimated that the annual instantaneous natural mortality of Bull Trout increased from 0.09 in 2009 to 0.78 in 2013; although it is worth noting that the upper estimate in 2009 was 0.27 and the lower estimate in 2013 was 0.27 .

The current study estimated that the annual instantaneous natural mortality of a non-spawning large Rainbow Trout was 0.27 compared to 0.88 for a spawner. The ecological, evolutionary and management implications of the mortality cost of spawning are discussed below. As the probability of spawning increased with body length the annual instantaneous natural mortality rate was also size-dependent.

To the best of our knowledge a direct estimate (Hoenig et al., 2016) of the natural mortality of large Rainbow Trout has not been published in the peer-reviewed literature. There are however numerous empirical (indirect) equations for calculating $M$ based on other life-history parameters (Then et al., 2015; Hamel, 2015). Based on over 200 fish species, (Then et al., 2015) recommended the maximum age $\left(t_{\max }\right)$ based estimator

$$
M=4.899 \cdot t_{\max }^{-0.916}
$$

when possible and the growth-based method

$$
M=4.188 \cdot k^{0.73} \cdot L_{\infty}^{-0.33}
$$

otherwise. When applied to large Rainbow Trout in Kootenay Lake with $t_{\max }=8$ (Andrusak and Andrusak, 2015), $k=0.19$ (Andrusak and Thorley, 2014) and $L_{\infty}=1000$, the estimated values of $M$ are 0.73 using Equation 21 and 0.13 using Equation 22. The discrepancy in the empirical estimates as well as their inability to account for annual and length-based variation in $M$ indicates the limitations of an indirect approach to estimating the natural mortality of large piscivorous trout.

\section{Inter-annual Variability}

The CJS model strongly supported an increase in the natural mortality of Bull Trout over the course of the study. Further support for an increase in Bull Trout natural mortality is also provided by a preliminary redd count analysis for Kootenay Lake (Andrusak and Andrusak, 2014) that suggests a lake-wide decrease in the number of spawners from a peak in 2009 to a low in 2013 (the last year of the redd count study). As the CJS model provided little support for a change in the probability of Bull Trout spawning the decline in the number of Bull Trout spawners likely reflects a decline in Bull Trout abundance. The finding that $M$ has changed over the course of the study is important because it is consistent with Kokanee abundance or another biological factor as a driver of short-term Bull Trout population dynamics.

The CJS model only provided moderate support for an increase in the natural mortality of Rainbow Trout. More specifically the CJS model estimated that the annual instantaneous natural mortality of a non-spawning Rainbow Trout increased from 0.13 in 2008 to 0.47 in 2013. In contrast, Rainbow Trout escapement, as estimated by Area-Under-the Curve analysis with a residence time of seven days (Hagen et al., 2010), increased from 1,583 in 2008 to a high of 3,289 in 2012 before falling slightly in the spring of the final year of the current study (Fig. 10). While the escapement was increasing to record levels the probability of spawning was declining dramatically. This finding is important because it suggests that the actual increase in the number of large Rainbow Trout was even more dramatic than indicated by the escapement. 


\section{Spawning}

For Bull Trout the CJS model did not identify an increase in the mortality rate associated with spawning. However, as discussed above spawners which died prior to returning to Kootenay Lake would have been misidentified as inlake mortalities. It is therefore likely that the natural mortality of spawners and non-spawners are under and over-estimated, respectively.

For Rainbow Trout, spawning increased the annual interval natural mortality rate from $23 \%$ to $59 \%$. The high spawning mortality is consistent with the limited spawning area and high levels of antagonistic interactions at the outflow of Trout Lake (Hartman, 1969; Hartman and Galbraith, 1970). The high spawning mortality may also explain why the probability of spawning is low for Kootenay Lake Rainbow Trout smaller than approximately $650 \mathrm{~mm}$ in length, i.e., the cost of spawning selects for delayed maturation.

\section{Population Fluctuations}

There was no evidence for a change in the fishing mortality over the course of the study but strong and moderate evidence for an increase in the natural mortality of Bull Trout and Rainbow Trout, respectively. These results are consistent with Kokanee or another biological factor, as opposed to anglers, as the driver of the short-term fluctuations in the Rainbow Trout population. Evidence for a role of Kokanee is provided by the numbers (Fig. 10) and sizes (Fig. 11) of Kokanee spawners at the Meadow Creek spawning channel and the Lardeau River (MFLNRO, 2016).

An additional key finding is that the probability of spawning declined dramatically for Rainbow Trout over the course of the study. Given the high mortality cost of spawning, any reduction in the energy available for gamete production associated with the decline in Kokanee abundance might cause fish to delay spawning. An important implication of this potential relationship is that Rainbow Trout escapement at the outflow to Trout Lake may be a less reliable index of population abundance than previously assumed. Perhaps due to their density-dependent phenotypic plasticity the probability of spawning remained constant for Bull Trout (Johnston and Post, 2009).

It is important to note that the results of the current study do not preclude changes in angler effort or lake productivity as drivers of longer-term trends in abundance. Indeed in a recent modelling study Kurota et al. (2016) concluded that the peak in Rainbow Trout in 2012 was caused by a longer-term increase in recruitment combined with a longer-term reduction in $F$.

Based on the recapture rates and creel survey catch estimates, the current study found that in 2011 large Bull Trout were at least as abundant as large Rainbow Trout in Kootenay Lake. This finding is important because it means that multi-species population models such as that developed by Kurota et al. (2016) need to be expanded to take Bull Trout into account.

\section{ACKNOWLEDGMENTS}

We thank Robyn Irvine (Poisson Consulting), Harvey Andrusak (Redfish Consulting), Matt Neufeld (MFLNRO), Jeff Burrows (MFLNRO), James Baxter (FWCP) and others for assisting with fish capture and tagging; Kerry Reed (Reel Adventures) and Alan Richardson (Magic Charters) for providing guide services; Kerry Reed for tagging the fish in 2012 and 2013; Sarah Stephenson (MFLNRO) and Matt Neufeld for maintaining and downloading the acoustic receiver array; all the anglers who reported recaptures; MFLNRO staff for recording the reported recaptures; Gary Pavan for processing the detection and capture data and creating the lake sections; Bernhard Konrad for providing code to check the consistency of detections; and Harvey Andrusak, Steve Arndt (MFLNRO), Crystal Klym (FWCP) and Robyn Irvine for providing comments on earlier drafts. We particularly thank Jeff Burrows and Matt Neufeld for supporting the project.

\section{REFERENCES}

Anderson, W. G., McKinley, R. S., and Colavecchia, M. (1997). The Use of Clove Oil as an Anesthetic for Rainbow Trout and Its Effects on Swimming Performance. North American Journal of Fisheries Management, 17(2):301-307.

Andrusak, G. and Andrusak, H. (2014). Bull Trout redd count surveys in select Kootenay Lake tributaries (2013) and recommendations for future surveys. A Redfish Consulting Ltd. Report, Fish and Wildlife Compensation Program, Castlegar, B.C. 
Andrusak, G. and Thorley, J. (2014). Kootenay Lake Exploitation Study: A combined tag-telemetry approach to estimate fishing and natural mortality of large Bull Trout and Rainbow Trout on Kootenay Lake, British Columbia - 2014 Annual Report. A Poisson Consulting Ltd. and Redfish Consulting Ltd. Report 10.13140/RG.2.1.3116.2644, Habitat Conservation Trust Foundation, Victoria, BC.

Andrusak, G. F. and Andrusak, H. (2015). Gerrard Rainbow Trout Growth and Condition with Kokanee Prey at Low Densities. A Redfish Consulting Ltd. Report F-F15-15, Fish and Wildlife Compensation Program - Columbia, Nelson, BC.

Andrusak, H. and Andrusak, G. F. (2012). Kootenay Lake Angler Creel Survey 2011. A Redfish Consulting Ltd. Report, Fish and Wildlife Compensation Program - Columbia Basin, Nelson, BC.

Andrusak, H. and Parkinson, E. (1984). Food Habitats of Gerrard Stock Rainbow Trout in Kootenay Lake, British Columbia. Technical Report 60, Fish and Wildlife Branch.

Askey, P. J., Richards, S. A., Post, J. R., and Parkinson, E. A. (2006). Linking angling catch rates and fish learning under catch-and-release regulations. North American Journal of Fisheries Management, 26(4):1020-1029.

Bacheler, N. M., Buckel, J. A., Hightower, J. E., Paramore, L. M., and Pollock, K. H. (2009). A combined telemetry - tag return approach to estimate fishing and natural mortality rates of an estuarine fish. Canadian Journal of Fisheries and Aquatic Sciences, 66(8):1230-1244.

Barbour, A. B., Ponciano, J. M., and Lorenzen, K. (2013). Apparent survival estimation from continuous mark-recapture/resighting data. Methods in Ecology and Evolution, 4(9):846-853.

Bartholomew, A. and Bohnsack, J. A. (2005). A Review of Catch-and-Release Angling Mortality with Implications for No-take Reserves. Reviews in Fish Biology and Fisheries, 15(1-2):129-154.

Biro, P. A. (2013). Are most samples of animals systematically biased? Consistent individual trait differences bias samples despite random sampling. Oecologia, 171(2):339-345.

Bison, R., O'Brien, D., and Martell, S. J. (2003). An Analysis of Sustainable Fishing Options for Adams Lake Bull Trout Using Life History and Telemetry Data. Technical report, BC Ministry of Water Land and Air Protection, Kamloops, B.C.

Brenden, T. O., Jones, M. L., and Ebener, M. P. (2010). Sensitivity of tag-recovery mortality estimates to inaccuracies in tag shedding, handling mortality, and tag reporting. Journal of Great Lakes Research, 36:100-109.

Brooks, S. and Gelman, A. (1998). General methods for monitoring convergence of iterative simulations. Journal of Computational and Graphical Statistics, 7(4):434-455.

Brown, R. S., Cooke, S. J., Anderson, W. G., and McKinley, R. S. (1999). Evidence to Challenge the "2\% Rule" for Biotelemetry. North American Journal of Fisheries Management, 19(3):867-871.

Cormack, R. M. (1964). Estimates of Survival from the Sighting of Marked Animals. Biometrika, 51(3/4):429.

Daley, R., Carmack, E., and Gray, C. (1981). Effects of upstream impoundments on the limnology of Kootenay Lake, BC.

Fabrizio, M. C., Nichols, J. D., Hines, J. E., Swanson, B. L., and Schram, S. T. (1999). Modeling data from double-tagging experiments to estimate heterogeneous rates of tag shedding in lake trout (Salvelinus namaycush). Canadian Journal of Fisheries and Aquatic Sciences, 56(8):1409-1419.

Gelman, A. (2014). Bayesian data analysis. Chapman \& Hall/CRC texts in statistical science. CRC Press, Boca Raton, third edition edition.

George, E. I. and McCulloch, R. E. (1993). Variable Selection via Gibbs Sampling. Journal of the American Statistical Association, 88(423):881-889.

Gutowsky, L., Harrison, P., Martins, E., Leake, A., Patterson, D., Power, M., and Cooke, S. (2013). Diel vertical migration hypotheses explain size-dependent behaviour in a freshwater piscivore. Animal Behaviour, 86(2):365-373.

Gutowsky, L., Harrison, P., Martins, E., Leake, A., Patterson, D., Power, M., and Cooke, S. (2016). Interactive effects of sex and body size on the movement ecology of adfluvial bull trout ( Salvelinus confluentus ). Canadian Journal of Zoology, 94(1):31-40.

Hagen, J., Baxter, J., Burrows, J., and Bell, J. (2010). Gerrard Rainbow Trout (Oncorhynchus mykiss) Spawner Migration and Residence Time as Estimated by Radio and Sonic Telemetry, 2004-2009. A John Hagen and Associates Report, Fish and Wildlife Compensation Program, Nelson, BC, Nelson, $\mathrm{BC}$.

Hamblin, P. F. and McAdam, S. O. (2003). Impoundment effects on the thermal regimes of Kootenay 
Lake, the Arrow Lakes Reservoir and Upper Columbia River. Hydrobiologia, 504(1-3):3-19.

Hamel, O. S. (2015). A method for calculating a meta-analytical prior for the natural mortality rate using multiple life history correlates. ICES Journal of Marine Science, 72(1):62-69.

Hartman, G. (1969). Reproductive Biology of the Gerrard Stock Rainbow Trout. In Northcote, T., editor, Symposium on salmon and trout in streams, pages 53-67, Vancouver, B.C. University of British Columbia.

Hartman, G. and Galbraith, D. (1970). The Reproductive Environment of the Gerrard Stock Rainbow Trout. Fisheries Management Publication 15, Fish and Wildlife Branch, Victoria, BC.

Hightower, J. E., Jackson, J. R., and Pollock, K. H. (2001). Use of Telemetry Methods to Estimate Natural and Fishing Mortality of Striped Bass in Lake Gaston, North Carolina. Transactions of the American Fisheries Society, 130(4):557-567.

Hilborn, R. (1992). Quantitative fisheries stock assessment: choice, dynamics, and uncertainty. Chapman and Hall, New York.

Hoenig, J. M., Then, A. Y.-H., Babcock, E. A., Hall, N. G., Hewitt, D. A., and Hesp, S. A. (2016). The logic of comparative life history studies for estimating key parameters, with a focus on natural mortality rate. ICES Journal of Marine Science: Journal du Conseil, page fsw089.

Hooten, M. B. and Hobbs, N. T. (2015). A guide to Bayesian model selection for ecologists. Ecological Monographs, 85(1):3-28.

Huhn, Daniel and Arlinghaus, Robert (2011). Determinants of hooking mortality in freshwater recreational fisheries: a quantitative meta-analysis. In The angler in the environment: social, economic, biological, and ethical dimensions: proceedings of the 5th World Recreational Fishing Conference, number 75 in American Fisheries Society symposium. Amer Fisheries Society, Bethesda, Md. OCLC: ocn741563434.

Huveneers, C., Simpfendorfer, C. A., Kim, S., Semmens, J., Hobday, A. J., Pederson, H., Stieglitz, T., Vallee, R., Webber, D., Heupel, M. R., Peddemors, V., and Harcourt, R. (2015). The influence of environmental parameters on the performance and detection range of acoustic receivers. Methods in Ecology and Evolution, pages n/a-n/a.

Irvine, J. (1978). The Gerrard Rainbow Trout of Kootenay Lake, British Columbia - A discussion of their life history with management, research and enhancement recommendations. Fisheries Management Report 72, Fish and Wildlife Branch, Victoria, BC.

Irvine, R., Baxter, J., and Thorley, J. (2013). Lower Duncan River Gerrard Rainbow Trout Monitoring 2013. A Mountain Water Research and Poisson Consulting Ltd. Report, BC Hydro, Castlegar, B.C.

Johnston, F. D. and Post, J. R. (2009). Density-dependent life-history compensation of an iteroparous salmonid. Ecological Applications, 19(2):449-467.

Jolly, G. M. (1965). Explicit estimates from capture-recapture data with both death and immigrationstochastic model. Biometrika, 52(1/2):225-247.

Keeley, E. R., Parkinson, E. A., and Taylor, E. B. (2005). Ecotypic differentiation of native rainbow trout (Oncorhynchus mykiss) populations from British Columbia. Canadian Journal of Fisheries and Aquatic Sciences, 62(7):1523-1539.

Keeley, E. R., Parkinson, E. A., and Taylor, E. B. (2007). The origins of ecotypic variation of rainbow trout: a test of environmental vs. genetically based differences in morphology. Journal of Evolutionary Biology, 20(2):725-736.

Kurota, H., McAllister, M. K., Parkinson, E., and Johnston, T. (2016). Evaluating the influence of predator-prey interactions on stock assessment and management reference points for a large lake ecosystem. Canadian Journal of Fisheries and Aquatic Sciences.

Kéry, M. (2010). Introduction to WinBUGS for Ecologists: A Bayesian approach to regression, ANOVA, mixed models and related analyses. Elsevier, Amsterdam; Boston.

Kéry, M. and Schaub, M. (2011). Bayesian population analysis using WinBUGS : a hierarchical perspective. Academic Press, Boston.

Matechou, E., Pledger, S., Efford, M., Morgan, B. J., and Thomson, D. L. (2013). Estimating age-specific survival when age is unknown: open population capture-recapture models with age structure and heterogeneity. Methods in Ecology and Evolution, 4(7):654-664.

Meyer, K. A., Elle, F. S., Lamansky, J. A., Mamer, E. R. J. M., and Butts, A. E. (2012). A RewardRecovery Study to Estimate Tagged-Fish Reporting Rates by Idaho Anglers. North American Journal of Fisheries Management, 32(4):696-703.

MFLNRO (2016). Kootenay Lake Action Plan 2016. A Redfish Consulting Ltd. Report, Mininstry of 
Forests, Lands and Natural Resource Operations, Nelson, BC.

Neufeld, M. D. and Rust, P. J. (2009). Using passive sonic telemetry methods to evaluate dispersal and subsequent movements of hatchery-reared white sturgeon in the Kootenay River. Journal of Applied Ichthyology, 25:27-33.

Northcote, T. (1973). Some impacts of man on Kootenay Lake and its salmonids. Technical Report Technical Report No, 25, Fish and Wildlife Branch, Victoria, BC.

Ntzoufras, I. (2009). Bayesian Modeling Using WinBUGS. John Wiley \& Sons Inc., Hoboken, New Jersey.

O'Brien, D. (2001). Bull Trout (Salvelinus confluentus) Spawning Migrations in the Duncan River: Insights from Telemetry and DNA. M.Sc., University of British Columbia, Vancouver, BC.

Paragamian, V. L. and Walters, J. P. (2011). Bull trout (Salvelinus confluentus) movement in a transboundary river. Journal of Freshwater Ecology, 26(1):65-76.

Plummer, M. (2015). JAGS version 4.0.1 user manual.

Pollock, K. H., Hoenig, J. M., Hearn, W. S., and Calingaert, B. (2001). Tag Reporting Rate Estimation: 1. An Evaluation of the High-Reward Tagging Method. North American Journal of Fisheries Management, 21(3):521-532.

Pollock, K. H., Jiang, H., and Hightower, J. E. (2004). Combining telemetry and fisheries tagging models to estimate fishing and natural mortality rates. Transactions of the American Fisheries Society, 133(3):639-648.

Post, J. R., Mushens, C., Paul, A., and Sullivan, M. (2003). Assessment of alternative harvest regulations for sustaining recreational fisheries: model development and application to bull trout. North American Journal of Fisheries Management, 23(1):22-34.

Prince, A. and Powell, C. (2000). Clove Oil as an Anesthetic for Invasive Field Procedures on Adult Rainbow Trout. North American Journal of Fisheries Management, 20(4):1029-1032.

Quinn, T. J. and Deriso, R. B. (1999). Quantitative fish dynamics. Oxford University Press, New York. OCLC: 434872106.

R Core Team (2015). R: A Language and Environment for Statistical Computing.

Royle, J. A. (2008). Modeling Individual Effects in the Cormack-Jolly-Seber Model: A State-Space Formulation. Biometrics, 64(2):364-370.

Schindler, E., Johner, D., Weir, T., Sebastien, D., Bassett, M., Vidmanic, L., and Ashley, K. (2014). Kootenay Lake Nutrient Restoration Program Years 20 and 21 (North Arm) and Years 8 and 9 (South arm) (2011 and 2012) Report. Technical report, Ministry of Forests, Lands and Natural Resource Operations, Nelson, B.C.

Seber, G. A. F. (1965). A Note on the Multiple-Recapture Census. Biometrika, 52(1/2):249.

Shuter, B. J., Jones, M. L., Korver, R. M., and Lester, N. P. (1998). A general, life history based model for regional management of fish stocks: the inland lake trout (Salvelinus namaycush) fisheries of Ontario. Canadian journal of fisheries and aquatic sciences, 55(9):2161-2177.

Stephenson, S. M., Neufeld, M. D., Ireland, S. C., Young, S., Hardy, R. S., and Rust, P. (2013). Survival and Dispersal of Sonic-Tagged, Hatchery-Reared Burbot Released into the Kootenay River. Transactions of the American Fisheries Society, 142(6):1671-1679.

Taylor, R. G., Whittington, J. A., Pine, W. E., and Pollock, K. H. (2006). Effect of Different Reward Levels on Tag Reporting Rates and Behavior of Common Snook Anglers in Southeast Florida. North American Journal of Fisheries Management, 26(3):645-651.

Then, A. Y., Hoenig, J. M., Hall, N. G., and Hewitt, D. A. (2015). Evaluating the predictive performance of empirical estimators of natural mortality rate using information on over 200 fish species. ICES Journal of Marine Science, 72(1):82-92.

Walters, C. J. and Martell, S. J. D. (2004). Fisheries Ecology and Management. Princeton University Press, Princeton, N.J.

Ward, H. G., Askey, P. J., Post, J. R., and Rose, K. (2013). A mechanistic understanding of hyperstability in catch per unit effort and density-dependent catchability in a multistock recreational fishery. Canadian Journal of Fisheries and Aquatic Sciences, 70(10):1542-1550.

Wickham, H. (2014). Tidy Data. Journal of Statistical Software, 59(10):1-22. 
FIGURES

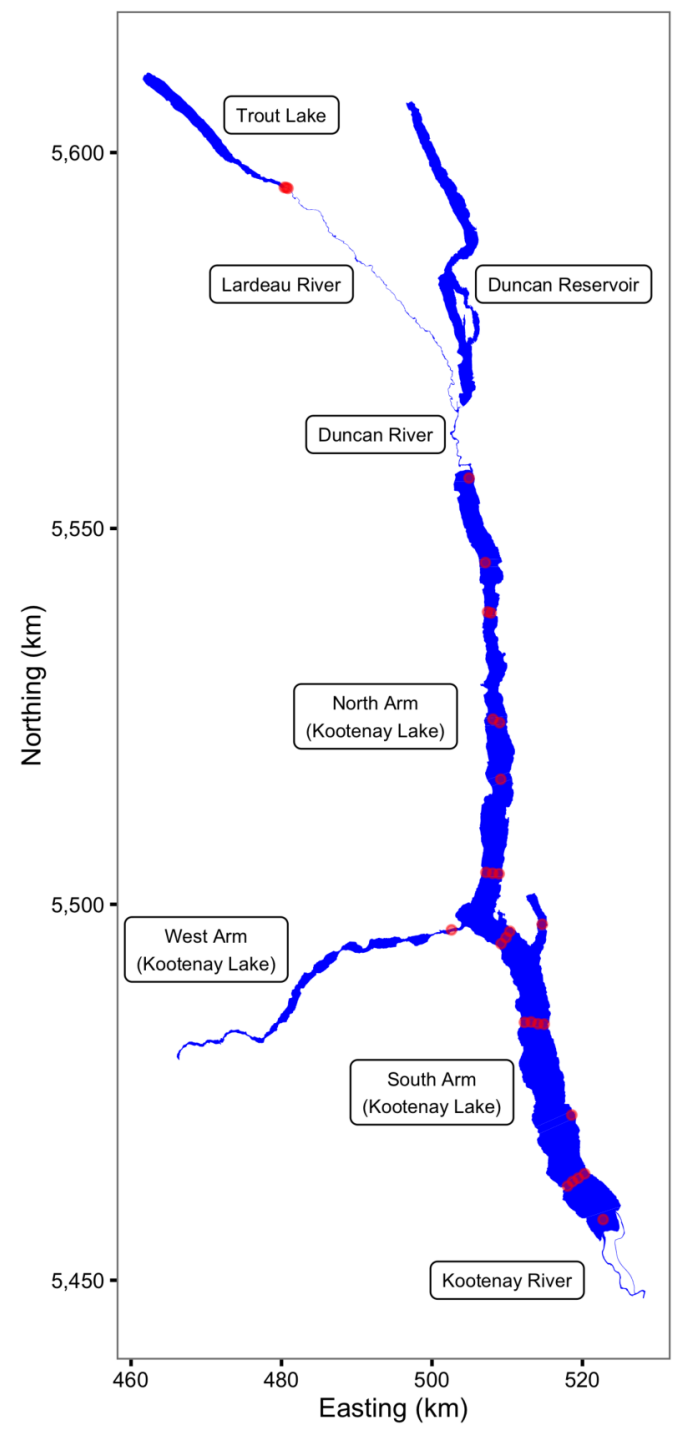

Figure 1. The study area including Kootenay Lake. The locations of the acoustic receivers are indicated by red circles. Spatial information licensed under the Open Government License of British Columbia. 


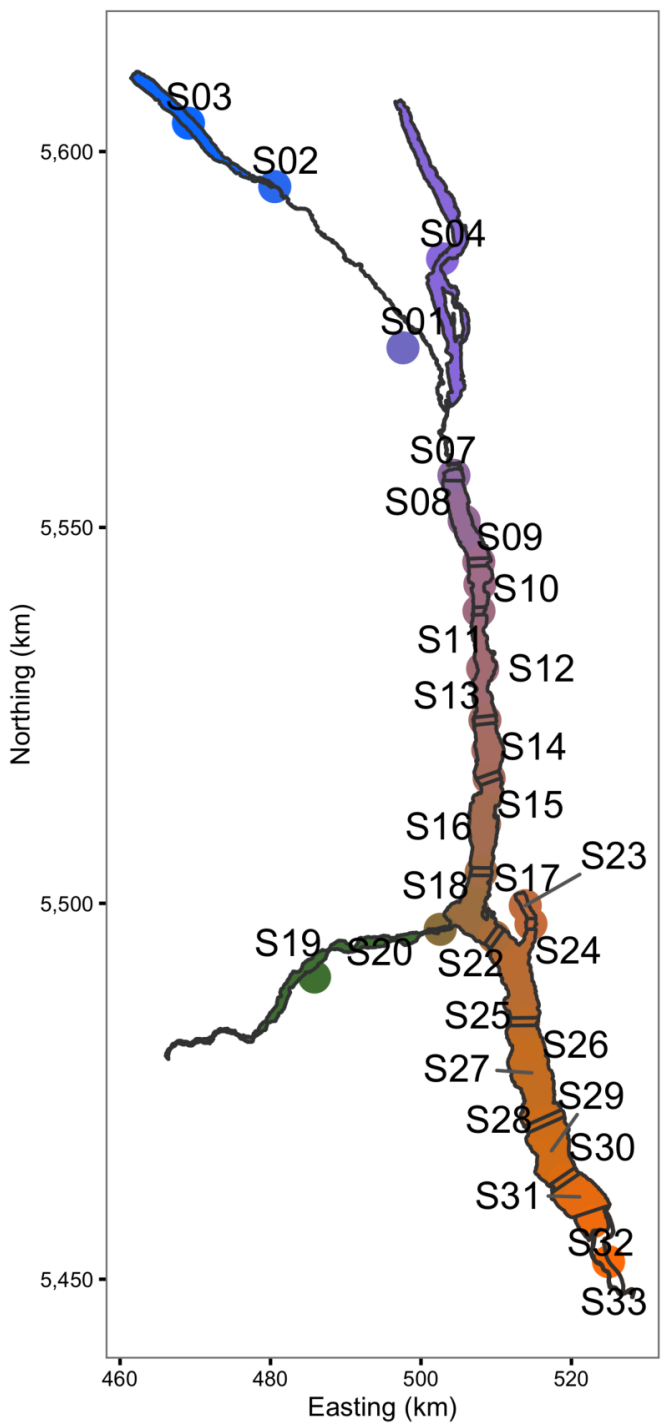

Figure 2. The study area including Kootenay Lake by color-coded section. The same color-coding scheme is used in the following two figures. Spatial information licensed under the Open Government License of British Columbia. 


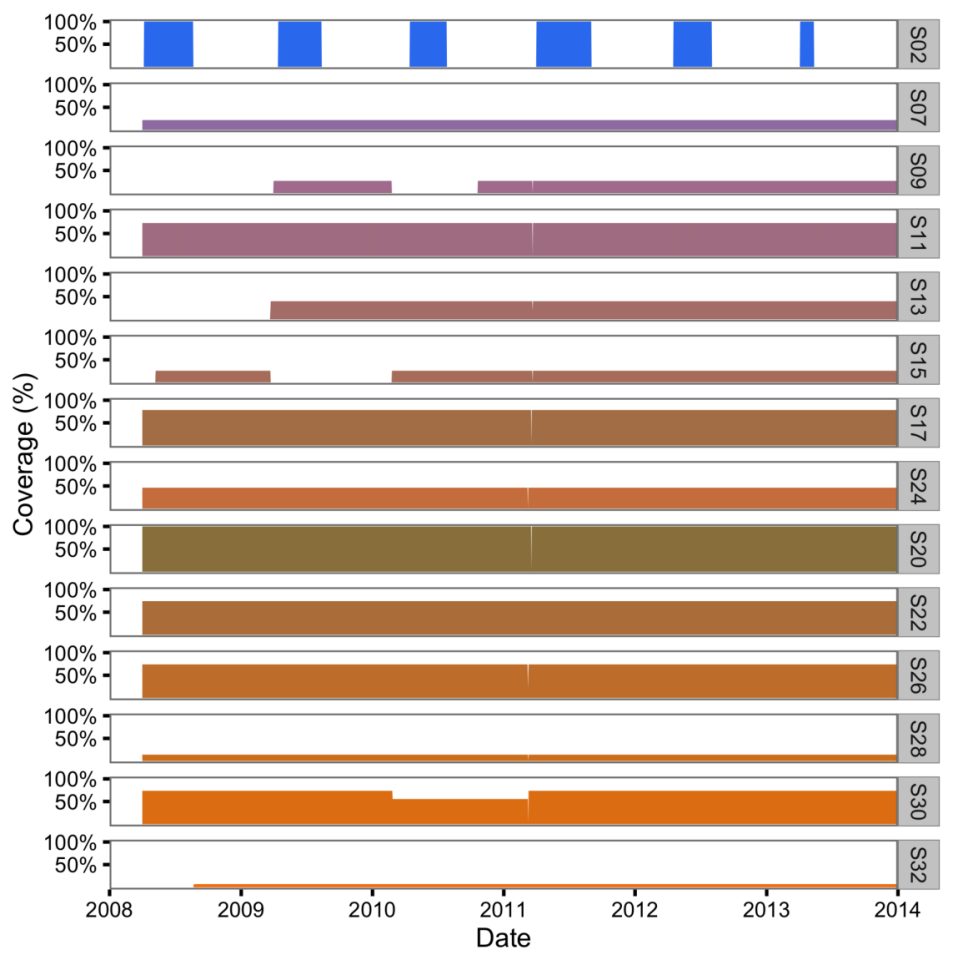

Figure 3. Daily acoustic receiver coverage in the study area by color-coded section. 


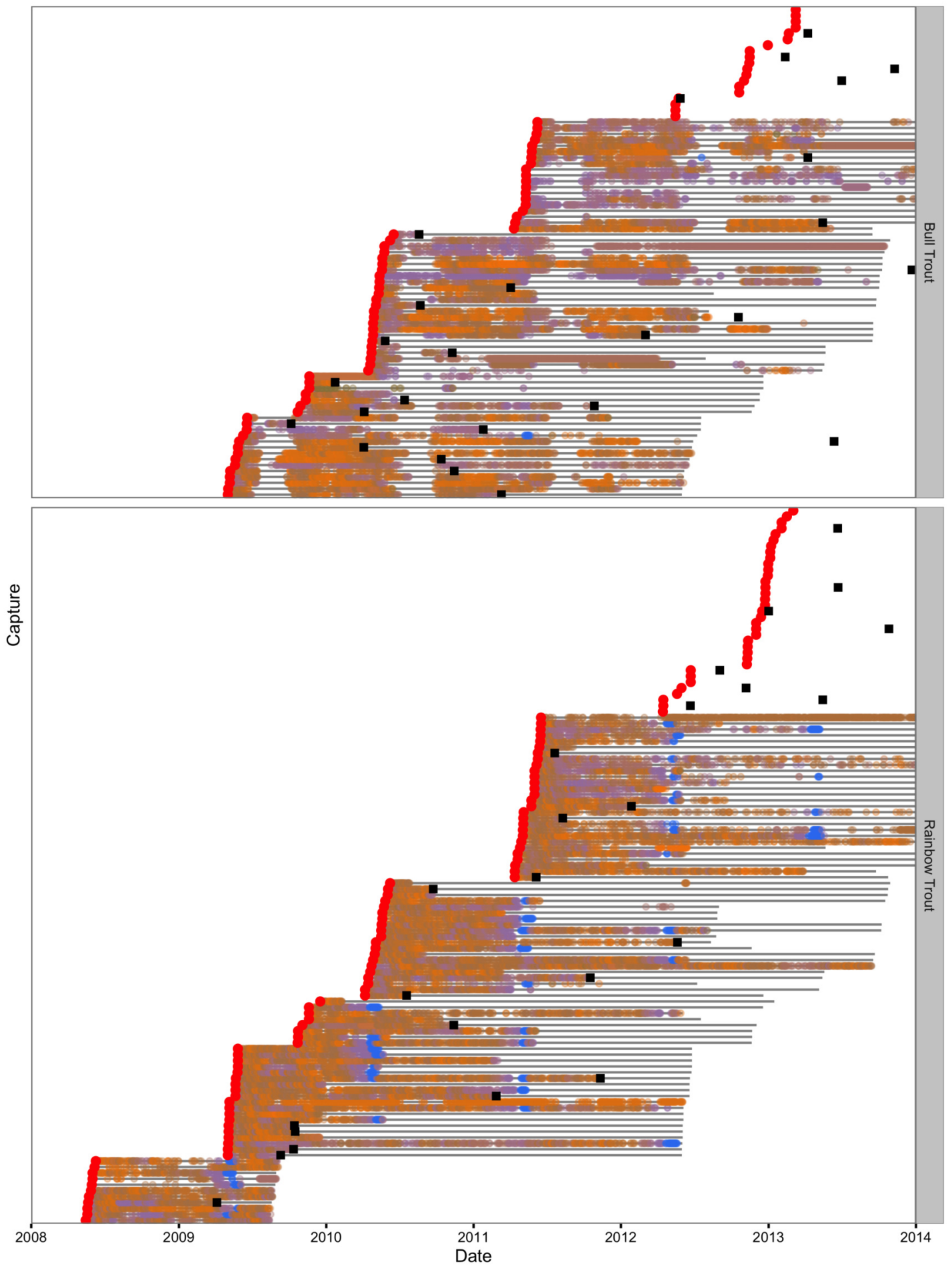

Figure 4. Daily acoustic detections in the study area by fish, species and color-coded section. Captures are indicated by the red circles, recaptures by the black squares and transmitter life by the horizontal grey lines. 


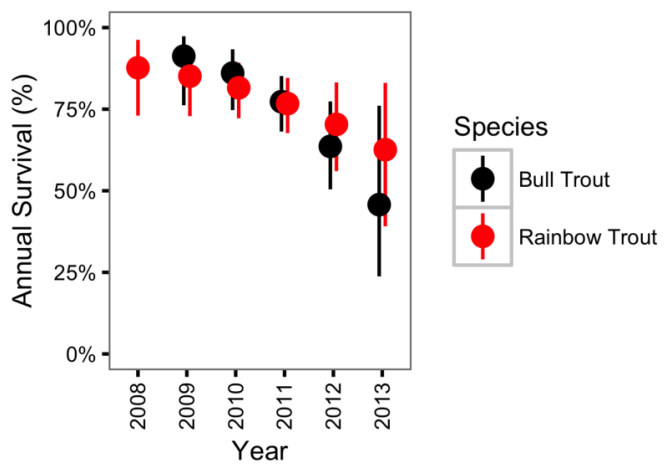

Figure 5. Estimated annual survival probabilities for non-spawning Bull Trout and Rainbow Trout by year. The bars represent 95\% CRIs. 


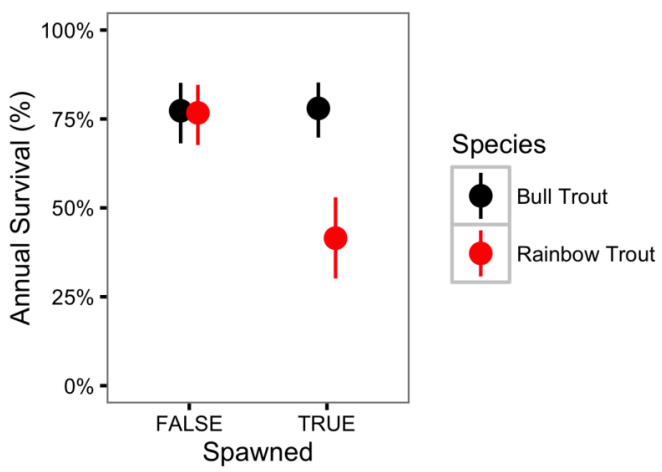

Figure 6. Estimated annual survival probabilities for Bull Trout and Rainbow Trout in 2011 by spawning status. The bars represent $95 \%$ CRIs. 


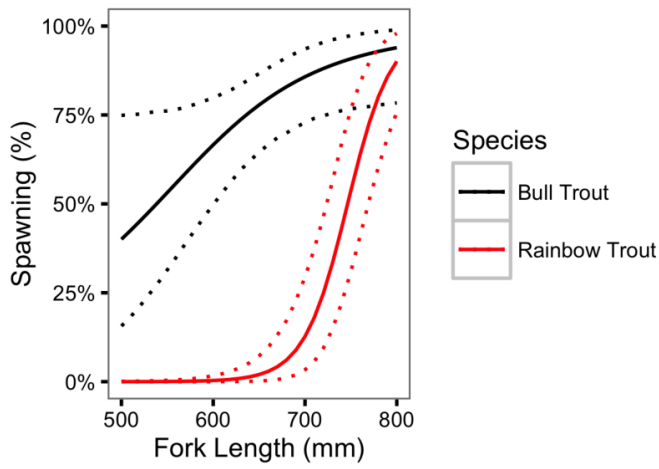

Figure 7. Estimated probability of spawning for Bull Trout and Rainbow Trout by fork length. The dotted lines represent $95 \%$ CRIs. 


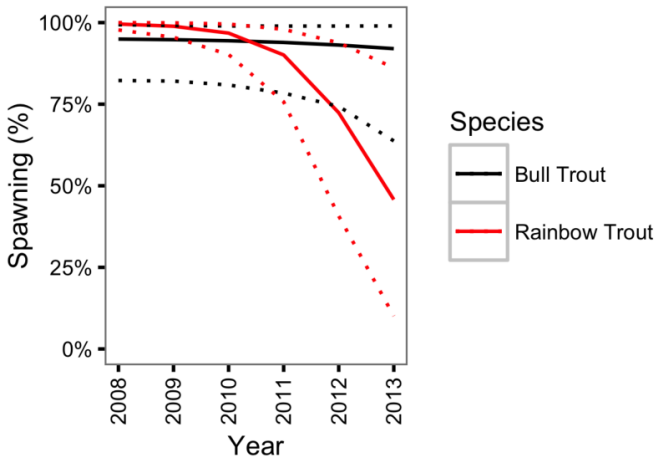

Figure 8. Estimated probability of spawning for a $800 \mathrm{~mm}$ Bull Trout and Rainbow Trout by year. The dotted lines represent $95 \%$ CRIs. 


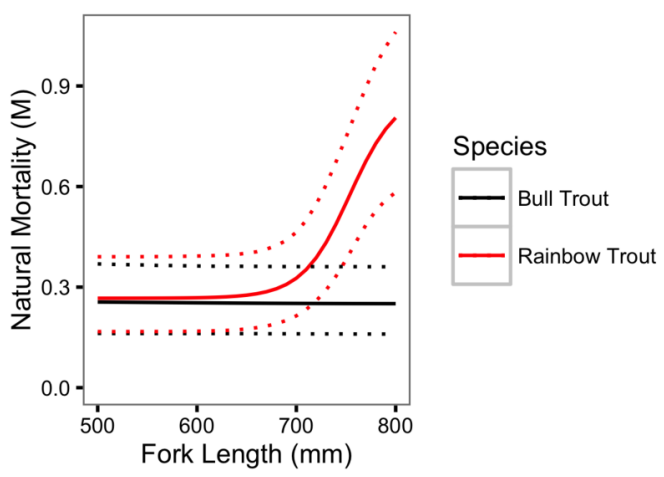

Figure 9. Estimated annual instantaneous natural mortality for Bull Trout and Rainbow Trout in 2011 by fork length. The dotted lines represent 95\% CRIs. 


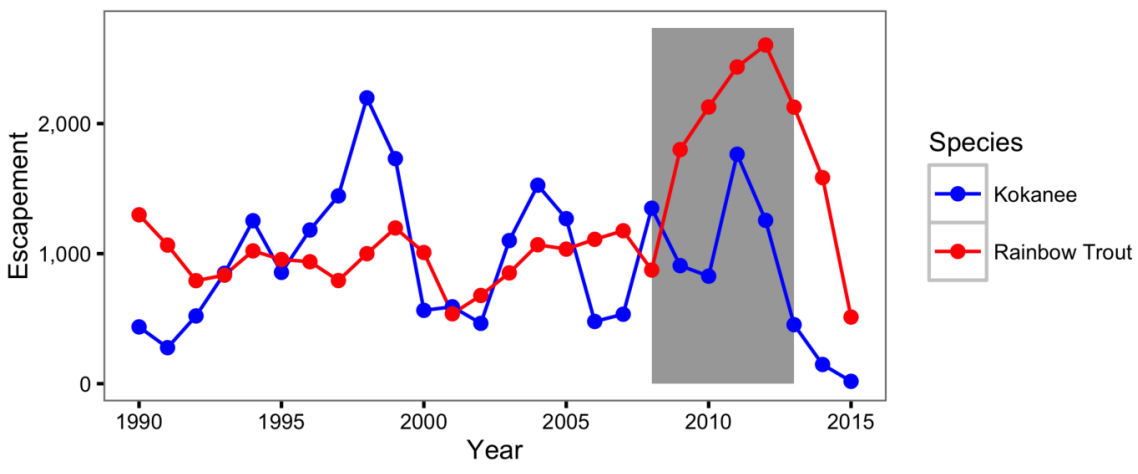

Figure 10. Rainbow Trout and Kokanee escapement by year. The Rainbow trout escapement is the spawner abundance at the outflow of Trout Lake. The Kokanee escapement is the spawner abundance at Meadow Creek and the Lardeau River. The grey rectangle indicates the period of the study from 2008 to 2013. 


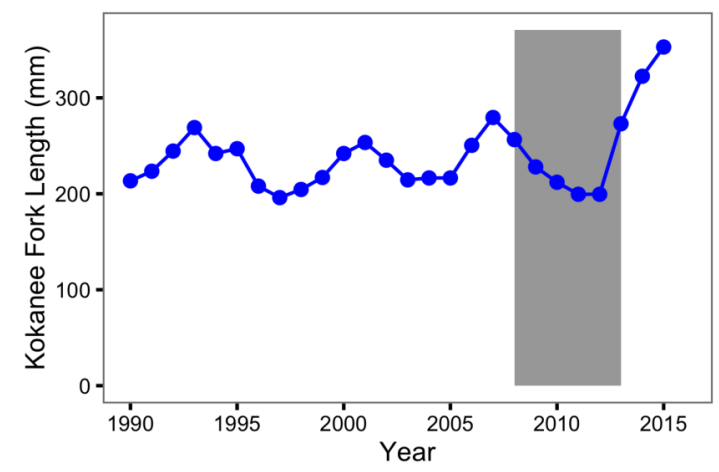

Figure 11. Kokanee spawner length by year. The lengths are the mean fork length at Meadow Creek Spawning Channel. The grey rectangle indicates the period of the study from 2008 to 2013. 
TABLES

\begin{tabular}{ll}
\hline Parameter & Description \\
\hline $\mathrm{Y}$ & The standardised year. \\
$\mathrm{L}$ & The calculated fork length. \\
$\beta_{\delta 0}$ & (FL - 600) / 100 \\
$\beta_{\delta S}$ & The log odds seasonal probability of being detected moving among sections. \\
$\beta_{\delta Y}$ & The effect of spawning season on $\beta_{\delta 0}$. \\
$\beta_{\kappa 0}$ & The loffect of $Y$ on $\beta_{\delta 0}$. \\
$\beta_{\kappa L}$ & The effect of $L$ on $\beta_{\kappa 0}$. \\
$\beta_{\kappa Y}$ & The effect of $Y$ on $\beta_{\kappa 0} \cdot$ \\
$\beta_{\phi 0}$ & The log odds seasonal probability of surviving. \\
$\beta_{\phi \kappa}$ & The effect of spawning on $\beta_{\phi 0}$. \\
$\beta_{\phi Y}$ & The effect of $Y$ on $\beta_{\phi 0}$. \\
$\beta_{\rho 0}$ & The log odds seasonal probability of being recaptured. \\
$\beta_{\rho Y}$ & The effect of $Y$ on $\beta_{\rho 0}$. \\
$\gamma_{\delta S}$ & The selection probability for $\beta_{\delta S}$. \\
$\gamma_{\delta Y}$ & The selection probability for $\beta_{\delta Y}$. \\
$\gamma_{\kappa L}$ & The selection probability for $\beta_{\kappa L}$. \\
$\gamma_{\kappa Y}$ & The selection probability for $\beta_{\kappa Y}$. \\
$\gamma_{\phi \kappa}$ & The selection probability for $\beta_{\phi \kappa}$. \\
$\gamma_{\phi Y}$ & The selection probability for $\beta_{\phi Y}$. \\
$\gamma_{\rho Y}$ & The selection probability for $\beta_{\rho Y}$. \\
\hline
\end{tabular}

Table 1. Descriptions for each of the parameters in the full CJS model. 


\begin{tabular}{rrrrr}
\hline Year & $\$ 100$ & $\$ 10$ & $\$ 0$ & No \\
\hline 2008 & 0 & 0 & 0 & 0 \\
2009 & 0 & 21 & 1 & 0 \\
2010 & 0 & 26 & 0 & 0 \\
2011 & 0 & 21 & 0 & 0 \\
2012 & 0 & 12 & 0 & 1 \\
2013 & 0 & 6 & 0 & 0 \\
\hline
\end{tabular}

Table 2. The number of captured Bull Trout by year and the value of the second anchor tag. All in cases the first anchor tag was a $\$ 100$ reward tag. With the exception of 2012 and 2013, the fish were also acoustically tagged. 


\begin{tabular}{rrrrr}
\hline Year & $\$ 100$ & $\$ 10$ & $\$ 0$ & No \\
\hline 2008 & 1 & 0 & 0 & 17 \\
2009 & 0 & 30 & 1 & 0 \\
2010 & 0 & 29 & 0 & 0 \\
2011 & 1 & 34 & 0 & 1 \\
2012 & 0 & 26 & 0 & 0 \\
2013 & 0 & 8 & 0 & 1 \\
\hline
\end{tabular}

Table 3. The number of captured Rainbow Trout by year and the value of the second anchor tag. All in cases the first anchor tag was a $\$ 100$ reward tag. With the exception of 2012 and 2013, the fish were also acoustically tagged. 


\begin{tabular}{lrrrr}
\hline Section & Winter & Spring & Summer & Autumn \\
\hline S07 & 0 & 6 & 1 & 0 \\
S09 & 0 & 1 & 0 & 2 \\
S11 & 0 & 1 & 1 & 1 \\
S13 & 0 & 2 & 1 & 0 \\
S15 & 1 & 0 & 0 & 0 \\
S17 & 0 & 2 & 0 & 1 \\
S24 & 1 & 0 & 0 & 1 \\
S20 & 0 & 0 & 0 & 1 \\
S22 & 1 & 0 & 0 & 0 \\
S26 & 0 & 1 & 0 & 0 \\
S30 & 0 & 1 & 0 & 1 \\
\hline
\end{tabular}

Table 4. The number of Bull Trout last detected at each section by season. Only individuals that were last detected at least 120 days before the end of their transmitter life and were not subsequently recaptured are included. 


\begin{tabular}{lrrrr}
\hline Section & Winter & Spring & Summer & Autumn \\
\hline S02 & 0 & 11 & 0 & 0 \\
S07 & 0 & 7 & 0 & 0 \\
S09 & 1 & 0 & 0 & 0 \\
S11 & 0 & 3 & 1 & 1 \\
S17 & 0 & 0 & 1 & 1 \\
S24 & 0 & 0 & 1 & 1 \\
S20 & 1 & 2 & 1 & 0 \\
S22 & 1 & 2 & 0 & 1 \\
S26 & 2 & 2 & 0 & 0 \\
S28 & 0 & 0 & 1 & 0 \\
S30 & 2 & 0 & 1 & 1 \\
S32 & 0 & 3 & 0 & 0 \\
\hline
\end{tabular}

Table 5. The number of Rainbow Trout last detected at each section by season. Only individuals that were last detected at least 120 days before the end of their tranmitter life and were not subsequently recaptured are included. 


\begin{tabular}{lrrrrrr}
\hline Parameter & Estimate & Lower & Upper & SD & Error & Significance \\
\hline$\beta_{\delta 0}$ & 2.358 & 1.987 & 2.772 & 0.200 & 17 & 0.0001 \\
$\beta_{\delta S}$ & -2.399 & -2.957 & -1.864 & 0.279 & 23 & 0.0001 \\
$\beta_{\delta Y}$ & -0.3732 & -0.9867 & 0.0342 & 0.3290 & 140 & 0.2642 \\
$\beta_{\kappa 0}$ & 2.429 & 1.192 & 3.589 & 0.589 & 49 & 0.0001 \\
$\beta_{\kappa L}$ & 1.147 & 0.027 & 1.970 & 0.433 & 85 & 0.0248 \\
$\beta_{\kappa Y}$ & -0.1275 & -1.1673 & 0.1006 & 0.3408 & 500 & 0.8014 \\
$\beta_{\phi K}$ & 0.3302 & -0.3992 & 3.4160 & 0.9492 & 580 & 0.8190 \\
$\beta_{\phi 0}$ & 2.728 & 2.296 & 3.195 & 0.227 & 16 & 0.0001 \\
$\beta_{\phi Y}$ & -0.9816 & -1.6406 & -0.0110 & 0.3730 & 83 & 0.0368 \\
$\beta_{\rho 0}$ & -3.065 & -3.479 & -2.688 & 0.202 & 13 & 0.0001 \\
$\beta_{\rho Y}$ & 0.01149 & -0.08315 & 0.26485 & 0.09349 & 1500 & 0.9466 \\
$\gamma_{\delta S}$ & 1.000 & 1.000 & 1.000 & 0.000 & 0 & 0.0001 \\
$\gamma_{\delta Y}$ & 0.6408 & 0.0000 & 1.0000 & 0.4798 & 78 & 0.0001 \\
$\gamma_{\kappa L}$ & 0.9657 & 0.0000 & 1.0000 & 0.1820 & 52 & 0.0001 \\
$\gamma_{K Y}$ & 0.2291 & 0.0000 & 1.0000 & 0.4203 & 220 & 0.0001 \\
$\gamma_{\phi \kappa}$ & 0.2902 & 0.0000 & 1.0000 & 0.4539 & 170 & 0.0001 \\
$\gamma_{\phi Y}$ & 0.9538 & 0.0000 & 1.0000 & 0.2099 & 52 & 0.0001 \\
$\gamma_{\rho Y}$ & 0.09250 & 0.00000 & 1.00000 & 0.28970 & 540 & 0.0001 \\
\hline
\end{tabular}

Table 6. Key fixed parameter estimates for the final Bull Trout CJS survival model. The columns are the parameter name, the point estimate, the lower and upper $95 \%$ credible intervals, the standard deviation $(S D)$, the percent relative error, and the statistical significance. 


\begin{tabular}{lrrrrrr}
\hline Parameter & Estimate & Lower & Upper & SD & Error & Significance \\
\hline$\beta_{\delta 0}$ & 2.975 & 2.543 & 3.502 & 0.242 & 16 & 0.0001 \\
$\beta_{\delta S}$ & -0.08340 & -0.91220 & 0.10070 & 0.25880 & 610 & 0.8392 \\
$\beta_{\delta Y}$ & -0.004190 & -0.234280 & 0.158230 & 0.099260 & 4700 & 0.9886 \\
$\beta_{\kappa 0}$ & 0.1600 & -0.8004 & 1.1863 & 0.5032 & 620 & 0.7558 \\
$\beta_{\kappa L}$ & 4.457 & 2.876 & 6.296 & 0.874 & 38 & 0.0001 \\
$\beta_{\kappa Y}$ & -2.153 & -3.504 & -0.963 & 0.651 & 59 & 0.0010 \\
$\beta_{\phi \kappa}$ & -2.671 & -3.393 & -1.965 & 0.366 & 27 & 0.0001 \\
$\beta_{\phi 0}$ & 2.697 & 2.277 & 3.154 & 0.225 & 16 & 0.0001 \\
$\beta_{\phi Y}$ & -0.4681 & -1.0209 & 0.0283 & 0.3196 & 110 & 0.1818 \\
$\beta_{\rho 0}$ & -3.289 & -3.715 & -2.895 & 0.210 & 12 & 0.0001 \\
$\beta_{\rho Y}$ & 0.01512 & -0.06594 & 0.27639 & 0.08644 & 1100 & 0.9008 \\
$\gamma_{\delta S}$ & 0.1963 & 0.0000 & 1.0000 & 0.3972 & 260 & 0.0001 \\
$\gamma_{\delta Y}$ & 0.09930 & 0.00000 & 1.00000 & 0.29910 & 500 & 0.0001 \\
$\gamma_{\kappa L}$ & 1.000 & 1.000 & 1.000 & 0.000 & 0 & 0.0001 \\
$\gamma_{\kappa Y}$ & 0.9983 & 1.0000 & 1.0000 & 0.0412 & 0 & 0.0001 \\
$\gamma_{\phi K}$ & 1.000 & 1.000 & 1.000 & 0.000 & 0 & 0.0001 \\
$\gamma_{\phi Y}$ & 0.7645 & 0.0000 & 1.0000 & 0.4243 & 65 & 0.0001 \\
$\gamma_{\rho Y}$ & 0.08730 & 0.00000 & 1.00000 & 0.28230 & 570 & 0.0001 \\
\hline
\end{tabular}

Table 7. Key fixed parameter estimates for the final Rainbow Trout CJS survival model. The columns are the parameter name, the point estimate, the lower and upper $95 \%$ credible intervals, the standard deviation $(S D)$, the percent relative error, and the statistical significance. 